\title{
Industrial Elaboration by Extrusion of PVC Tubes Loaded with Micronized Dura Palm Kernel Shell Powder
}

\section{Rolland Djomi1 ${ }^{*}$, Christian Mbopda Fokam1, Florent Biyeme1, Chantal Marguerite Mveh2, Roland Olembé1, Hypolyte Ntede ${ }^{1}$, Ateba Atangana ${ }^{3}$}

${ }^{1}$ Civil and Mechanical Engineering Laboratory, National Advanced School of Engineering, University of Yaounde I, Yaounde, Cameroon

${ }^{2}$ Laboratory of Mathematical Engineering and Information System, National Advanced School of Engineering, University of Yaounde I, Yaounde, Cameroon

${ }^{3}$ Mechanics Laboratory, Higher Teachers' Technical Training College of Douala, Douala, Cameroon

Email: ^rdjomi@yahoo.fr

How to cite this paper: Djomi, R., Fokam, C.M., Biyeme, F., Mveh, C.M., Olembé, R., Ntede, H. and Atangana, A. (2021) Industrial Elaboration by Extrusion of PVC Tubes Loaded with Micronized Dura Palm Kernel Shell Powder. Journal of Materials Science and Chemical Engineering, 9, 41-69. https://doi.org/10.4236/msce.2021.910004

Received: September 20, 2021

Accepted: October 26, 2021

Published: October 29, 2021

Copyright $\odot 2021$ by author(s) and Scientific Research Publishing Inc. This work is licensed under the Creative Commons Attribution International License (CC BY 4.0).

http://creativecommons.org/licenses/by/4.0/

\begin{abstract}
We present in this work how to use the dura palm kernel shell powders as loads for the elaboration by extrusion of PVC tubes. The transformation of dura palm kernel shells into micronized shell powder as well as its characterization was the subject of recent work. We carried out, the formulations by using the industrial scales of precision, the mixtures of the instrants with an industrial machine of mark HENSHLLE $\mathrm{N}^{\circ} 2$ MAIN 570762, the routine tests by ATG/DSC then by IRTF, the extrusion of the tubes with an extruder twin-screw with 9 rooms of transformation finally the tests of conformity by the observations and the analyses. We obtained for the formulations the dosage of $0 \%, 4.01 \%, 12.54 \%, 23.03 \%, 32.01 \%, 38.01 \%, 51.02 \%$ representing the percentage of hull powder in the mixture, the machine mixing gave perfectly homogeneous powders, the routine tests showed that the hull powder keeps all its properties until the end of the shaping whatever the percentage of hulls contained in the PVC, the extrusion gave tubes for each formulation and the conformity tests gave perfectly round tubes of diameter $90 \times 82 \mathrm{~mm}$, a coloration going from white grey at $0 \%$ to dark black at $51.02 \%$ showing the influence of the carbon black and the color of the shell powder according to its proportion. The infrared of the tubes obtained shows for each formulation a variation of the $\mathrm{CH}_{2}$ and $\mathrm{CH}$ bonds and a decrease of the $-\mathrm{OH}$ bonds. The thermogravimetric analyses and the differential calorimetric analyses of the tubes of each formulation, show each time that the quantity of shell powders in the mixture influences the PVC tubes obtained. Thus, we obtain a variation
\end{abstract}


of the phase temperatures according to the dosage, giving from $108.72^{\circ} \mathrm{C}$ to $76.56^{\circ} \mathrm{C}$ for the glass transition temperature and from $494.71^{\circ} \mathrm{C}$ to $414.56^{\circ} \mathrm{C}$ for the melting temperature, at the DSC and a progressive decrease of the mass following the heat absorption with each time 4 phases instead of 5 for the unloaded PVC tubes at the ATG according to the dosage.

\section{Keywords}

Extrusion Elaboration of PVC Tubes, Micronized Dura Palm Kernel Shells, Routine Extrusion Test, Tube Conformity Test

\section{Introduction}

The work presented here has its importance in the environmental problems caused by plastics in general [1] and polyvinyl chlorides (PVC) in particular. The plastics production industries use minerals such as carbides, glass fibers, carbon fibers, silica [2], but especially calcium carbides, as a load during the production of plastics. Calcium carbide is a mineral material that is available in large quantities and is cheaper on the market. The disadvantage of a plastic material loaded with this carbide is that it does not degrade at the end of its life. Given their importance in society and the environmental problem they cause, it is necessary to replace the loads used with those that are biodegradable to have a biodegradable and recyclable material at the end of life.

Today, anti-pollution campaigns are making news around the world. Given the importance of plastics in society, the need to find a solution to make them degradable at the end of their life is of paramount importance and remains a major concern for researchers [3]. For this reason, more and more work on the feasibility of using plant fibers either as reinforcement or as a load for the manufacture of plastics is of concern to researchers. Several works have been carried out successfully in the use of mineral talc [4], wood [5], cactus, Alfa fiber [6] [7], Spanish broom fiber [8], date palm fiber [9], hemp [10] flax [11], ramie [12] sisal [13] in the form of fibers as a load (reinforcement) for the plastic material. The most striking results were: the ease of shaping (packaging, electricity, electronics...), the lightness of the plastic (the manufacture of automotive parts and aerospace and construction) [14], biodegradability and recyclability at the end of life. The advantages of synthetic polymers reinforced with vegetable fibers are numerous, namely the availability, low cost and abundance of fibers [5] [8] [13], which makes the reinforced plastics obtained inexpensive, renewable and non-toxic [1], all this next to other properties that it is no longer necessary to list.

The characteristics of the different natural fibers as loads or reinforcements for the manufacture of composites have already been described in the literature [5] [13]. The palm kernel dura nut powders of the oil palm plant of the family ARECACEAE (palmae) of its scientific name Elaeisguinensis Jacq, referenced by 
comparison to the botanical collection of TAMAKI MARUHASHI of the National Herbarium of Cameroon was the subject of the successful work in June 2018 for its use as a load during the production of plastics in general, by the team Djomi R. et al. in "Physicochemical and Thermal Characterization of Dura Palm Kernel Powder as a Load for Polymers: Case of Polyvinyl Chloride" [15]. They demonstrated that the oil palm variety is less exploited by farmers and less explored by researchers in several areas, but is found in very large quantities in the equatorial world in general and in Cameroon in particular. More and more the palm oil sector in the world in general and in Africa, in particular, is in full evolution. Thus, the successful use of palm kernel shell powders for the industrial production of extruded PVC tubes will bring a sensational addition to the oil palm sector.

The work encountered on the uses of plant loads and reinforcements is usually carried out in the laboratory. The transposition of experiments from laboratories to companies requires a lot of thought and is sometimes the subject of extensive research. PVC is one of the most widely used plastics in the industrial world. It is used in packaging, electronics, electrical, automotive, construction and other industries. PVC offers a great advantage in manufacturing because it can be mixed with other materials. This characteristic makes PVC a polymer that is in demand by researchers for the manufacture of new materials [16].

Polyvinyl chloride (PVC) tubes are one of the most widely used plastic materials in civil engineering today. They are mainly found in water and sewer pipes, ornaments, fences, poles for houses, and for scaffolding during slab construction. Extrusion is the most common forming technique used to produce tubes and the most delicate for forming plastics. It requires skill and refinement for both the technicians and the ingredients involved in shaping [16] [17]. Thus, the success of the work of the industrial elaboration by extrusion of PVC tubes using the powder of shells of palm kernel dura micronized will represent an exceptional challenge for the industrialists and for the researchers in the field. It is for this reason that the present work consists in using the powder of shells of palm kernel dura micronized to produce the tubes PVC in company by using an industrial extruder.

\section{Materials and Experimental Methods}

\subsection{The Framework of the Elaboration}

The elaboration was carried out at the SOFAMAC factory (Cameroonian materials manufacturing company) located in the central province, Mfoundi department, SOA district. It is an industrial company that produces plastic materials for construction, building, plumbing and household appliances. In order to confirm the palm kernel shell powder as a load and to allow the economic operators to be sure of the reliability of the results that we will bring, we have chosen an old company of the production of plastic materials to appreciate the results of 
the elaboration.

\subsection{The Materials}

The materials used for the shaping are as follows.

\subsubsection{The Resin}

The resin used is Polyvinyl Chloride (PVC) from DANSUK INDUSTRIAL Co, LTD of series No. S6830, PVC-S-70 [18].

The purchasing specifications for the PVC resin are shown in Table 1.

\subsubsection{Additives}

We used the additives listed in Table 2:

In recent years, research results have enabled the international standard for plastic processing, particularly for PVC tubes, to improve the chemical composition of certain additives. These additives either give poor results in the finished product or have a history of toxicity. Thus, the results of our PVC tubes with shell powders can also be improved. The work was carried out in a company that

Table 1. Characteristics of the raw PVC in the study.

\begin{tabular}{cc} 
Properties & Values \\
\hline Appearance & White powder \\
Degree of polymerisation & $12500-14500$ \\
Bulk density without tamping & $1.43-1.50$ \\
Bulk density after tamping & $1.53-1.63$ \\
Free flow & $\geq 10 \mathrm{~g} / \mathrm{s}$ \\
Moisture content & $\leq 0.3 \%$ \\
Sulphated ash & $\leq 0.1 \%$ \\
Fish eyes (number) & $\leq 20$ \\
Wet Screening Rejects & $\leq 0.01 \%$ \\
315 micron sieve & mounted on pallets. The product is well protected \\
250 micron sieve & against rainwater infiltration and humidity. \\
In $25 \mathrm{~kg}$ bags or in 1 tonne big bags. The big bags are & \\
&
\end{tabular}

Table 2. Additives in the PVC production of the study.

\begin{tabular}{ccc}
\hline markings & types of additives & names of additives \\
\hline 1 & Stabiliser & stadilox EP 1023 \\
2 & Lubricant & loxiole G 60 \\
3 & Plasticizer & di-oxyl phthalate (DOP) \\
4 & Titanium dioxide & titanium dioxide \\
5 & Colouring agent & carbon black \\
\hline
\end{tabular}


has been producing plastics for many years and the additives used comply with the relevant standards. According to the literature, the composition of the resin and additives as well as the loads authorised on the market must respect a minimum purity necessary for shaping [19] [20] [21].

\subsubsection{The Load}

The load is Dura Palm Kernel Shell Powder whose botanical characteristics, processing of the shells into micronized shell powder as well as characterizations were done in the article "Physicochemical and Thermal Characterization of Dura Palm Kernel Powder as a Load for Polymers: Case of Polyvinyl Chloride" [15].

\subsubsection{Materials}

Scale: Digital scale brand SEDITECH, precision 1/1000th.

Mixer: The mixer is a HENSHLLE No. 2 MAIN 570762. It has an upper hopper which allows the filling of the mixing chamber with a capacity of $1 \mathrm{~m}^{3}$ with a propeller at the end of the shaft which ensures the mixing of the powder. The mixing temperature ranges from $0^{\circ} \mathrm{C}$ to $150^{\circ} \mathrm{C}$ with an automatic control box and a wide speed range from $800 \mathrm{rpm}$ to $1750 \mathrm{rpm}$. An outlet is provided for the recovery of the mixed powder.

Thermogravimetric and thermodifferential analysis: The thermogravimetric and thermodifferential analyses were carried out on a LINSEIS STA PT-1000 $\mathrm{C}$ thermal analyser with the type Platinum Evaluation V1.0.182, coupled to a computer and programmed for this purpose. The thermal treatment of the device ranges from room temperature $\left(20^{\circ} \mathrm{C}-35^{\circ} \mathrm{C}\right)$ to $1000^{\circ} \mathrm{C}$. The heating rate varies between $1^{\circ} \mathrm{C}$ and $100^{\circ} \mathrm{C}$. The crucible is made of alumina oxide with a capacity of $150 \mathrm{mg}$ and a control crucible of alumina. The mass of the powder to be characterised is 20 to $25 \mathrm{mg}$. The load mass is between $100 \mathrm{mg}$ and $125 \mathrm{mg}$; the initial heating temperature depends on the ambient temperature at the time of measurement. The heating rate according to the literature is $10 \% \mathrm{~min}$. The computer plots the ATG/DSC thermograms by recording the data. We carry out the analyses in the Laboratories of Physicochemistry of Materials of the Faculty of Sciences of the University of Yaoundé 1-Cameroon. Fourier transformed infrared analysis: Fourier Transform Infrared spectroscopy (FT-IR) was performed using the Nicolet iS5 IR spectrometer.

\section{Fourier transformed infrared analysis:}

Fourier transform infrared (FT-IR) spectroscopy was performed using the Nicolet iS5 IR spectrometer. We recorded the IR spectra in ATR (attenuated total reflectance) mode on a germanium crystal [22]. FTIR spectra are obtained from the data records and we can trace our data in two parts: from 4000 - 500 $\mathrm{cm}^{-1}$ and from $500-400 \mathrm{~cm}^{-1}$. The samples are primed solid as a fine powder. The test conditions and test ranges are governed by the standard detailed in the manufacturer's catalogue [22]. This analysis was carried out at the Research Laboratory of Chemistry of Nuisances and Environmental Engineering (URCHINGE) University of Dschang-Cameroon. 


\section{Extrusion:}

The machine of the elaboration is a twin screw extruder including a hopper, a degassing machine, a twin screw barrel with 9 chambers (preheating + degassing + heating + shaping), the jaws, a sizing machine, a pulling machine, a cooling machine, a marking machine, and a dimensioning machine.

\subsection{Experimental Methodology of the Elaboration of PVC Tubes Loaded with Micronized Palm Kernel Shell Powder}

We experience a load for the production of PVC tubes. As we go along, we check the quality and success of the tubes we produce. Thus, Figure 1 gives us the process to respect to reach perfection.

Figure 1 shows that we must first have the material formulation. Then, we must proceed to a mixing that will provide a perfect homogeneity of the powder and predispose the set in the conditions of a perfect hysotropy of the material to obtain. We pass a routine test that consists in assuring the effectiveness of the shaping and situating ourselves on the quality of the results that we will obtain from the shaping. Thus the elaboration follows its course. From the results of the elaboration, we pass to the test of conformity which consists in redoing the routine tests this time on the elaborated material and to make a comparison of the results to those of the routine test and to the results of the works carried out in the field [16] [17] then to the standard governing the quality of the results in the field.

\subsubsection{Formulation}

We set the number of formulation starting with the production of unfilled PVC tubes i.e. having $0 \%$ of shell powder. Then, from the literature, the usual loads of calcium carbide are from $1 \%$ to $20 \%$ depending on the characteristics of the tube and the quality of the raw PVC [23]. Then, the loads and reinforcements encountered are limited to $60 \%$ incorporation in the resin. It is on this basis that we have chosen formulations with dosages in the vicinity of $5 \%, 10 \%, 20 \%, 30 \%$, $40 \%$ and $50 \%$. We have set the total mass at $100 \%$ and we have adopted the percentage of additives usually used in the production of PVC loaded with calcium carbide, and according to the standards.

\subsubsection{The Dosage}

We have chosen a fixed mass of the resin of $33.33 \mathrm{~kg}$, in order to limit the consumption of the resin of the factory. This limitation of the total mass of the resin is due to the fact that we are in the phase of experimentation.

Formulation $\Rightarrow \begin{gathered}\text { Mixing of the } \\ \text { elaborated } \\ \text { ingredients }\end{gathered} \rightarrow \begin{gathered}\text { Routine } \\ \text { test }\end{gathered} \rightarrow \begin{gathered}\text { Extrusion of } \\ \text { PVC pipes }\end{gathered} \quad \begin{gathered}\text { Conformity tests of } \\ \text { the tubes elaborated }\end{gathered}$

Figure 1. Schematic diagram of the elaboration of PVC tubes loaded with hull powder. 


\subsection{Mixing of the Ingredients of the Elaboration}

With the help of a SEDITECH digital scale, precision is $1 / 1000$ th. For each formulation, we measure the masses of the resin, additives and load and we record them in bags before starting the mixing. The mixer has a chamber equipped with a propeller to ensure automatic mixing at high temperature $\left(110^{\circ} \mathrm{C}\right)$. A control box is used to start the propeller and regulate the heating temperature.

\subsection{Experimental Methodology}

In the mixer of the blender, the powders of formulation F0 are introduced. The temperature and mixing time are programmed using the machine's control panel and turned on. As soon as the mixer stops, the powder is emptied and carefully conditioned for extrusion. The mixer is immediately cleaned. The same process is followed for all different formulations.

\subsection{Routine Test}

\subsubsection{Purpose of the Test}

The purpose of the routine test is to ensure the crystallographic cohesion of the formulation ingredients and to learn about the different values of crystallinity (Tcf), glass transition temperature $(\mathrm{Tg})$, melting temperature ( $\mathrm{Tf}$ ) of the mixture before shaping [4] [5] [8] [10]. To achieve our objectives, we made thermogravimetric and thermo differential analysis and then infrared analysis with fourier transform [23] [24].

\subsubsection{Test Tubes}

The specimens are blended powders of each formulation obtained in the HENSHLLE blender and carefully conditioned as shown in Figure 2, [25]. We prepared the samples in the extremes of the dosage i.e. dosage F0, F12.54, F32.01 and F51.02 in order to ensure the quality of the shaping.

\subsubsection{Gravimetric and Differential Thermal Analysis}

To ensure the extrusion of the PVC resin mixed with the shell powder, we analyzed the powders: shell, raw PVC, PVC loaded to $12.54 \%$ (F12.54), PVC loaded to $32.01 \%$ (F32.01), PVC loaded to 51.02\% (F51.02) and we observed the

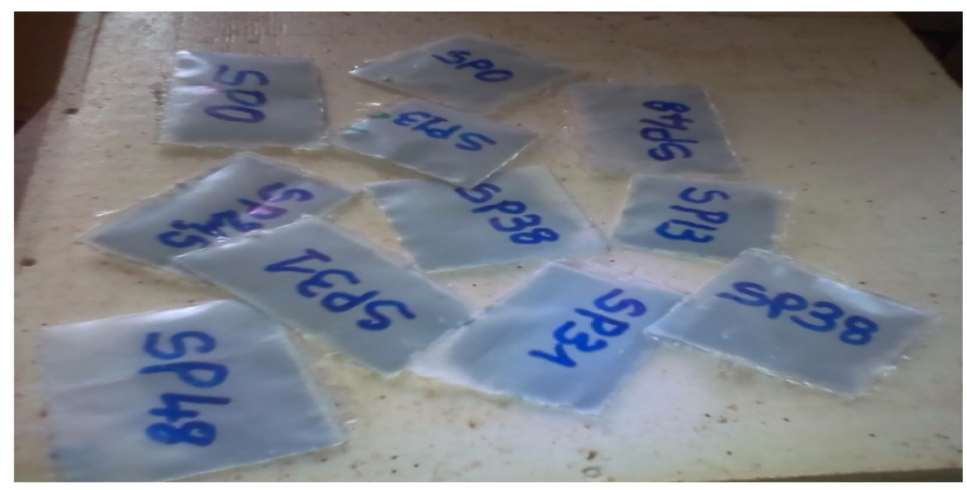

Figure 2. Mixing powder before extrusion for analysis. 
phenomena of the degradation of the shell powder and studied the feasibility before the shaping [15]. For this purpose, we primed the already mixed powders and took samples which we had analyzed by a LENSEI apparatus. The thermal behavior of the shell powder is obtained by interpretation of the TG and DSC thermograms performed by the LINSEI instrument of the Physico-chemistry of Mineral Materials Laboratory, Faculty of Science, University of Yaounde 1, Cameroon. The heating rate is $10 \% \mathrm{~min}$. The flue gas is oxygen. The crucible is alumina oxide of capacity $150 \mathrm{mg}$; the loading mass is $100 \mathrm{mg}$; the initial heating temperature is $20^{\circ} \mathrm{C}$ to $35^{\circ} \mathrm{C}$. We were given a thermogram TG coupled DSC with data records.

\subsubsection{Fourier Transform Infrared Spectrometric Analysis}

To obtain the different groupings that will form between the shell powder mixed in the PVC resin during and after extrusion, we analyzed the powders: shell, raw PVC, 12.54\% loaded PVC (F12.54), 32.01\% loaded PVC (F32.01), 51.02\% loaded PVC (F51.02). For this, we primed the already mixed powders in the mixer and ran them through the spectrometer. The FTIR analyses were carried out using the iS5 spectrometer. The spectra were acquired in the range of 4000 to $480 \mathrm{~cm}^{-1}$ at a resolution of $4 \mathrm{~cm}^{-1}$. Characteristic absorptions bands of the processed composites were registered.

\subsubsection{Extrusion Elaboration of PVC Tubes Loaded with Palm Kernel Shell Powder}

The materials are the powders mixed in the formulations F0, F4.01; F12.54; F23.03; F32.01; F38.01; F51.02 already passed to the mixer.

\section{Presentation of the twin screw extruder and extrusion:}

Figure 3 shows the twin screw extruder that we used in the SOFAMACYaoundé factory for the shaping of the tubes of our work as detailed in the

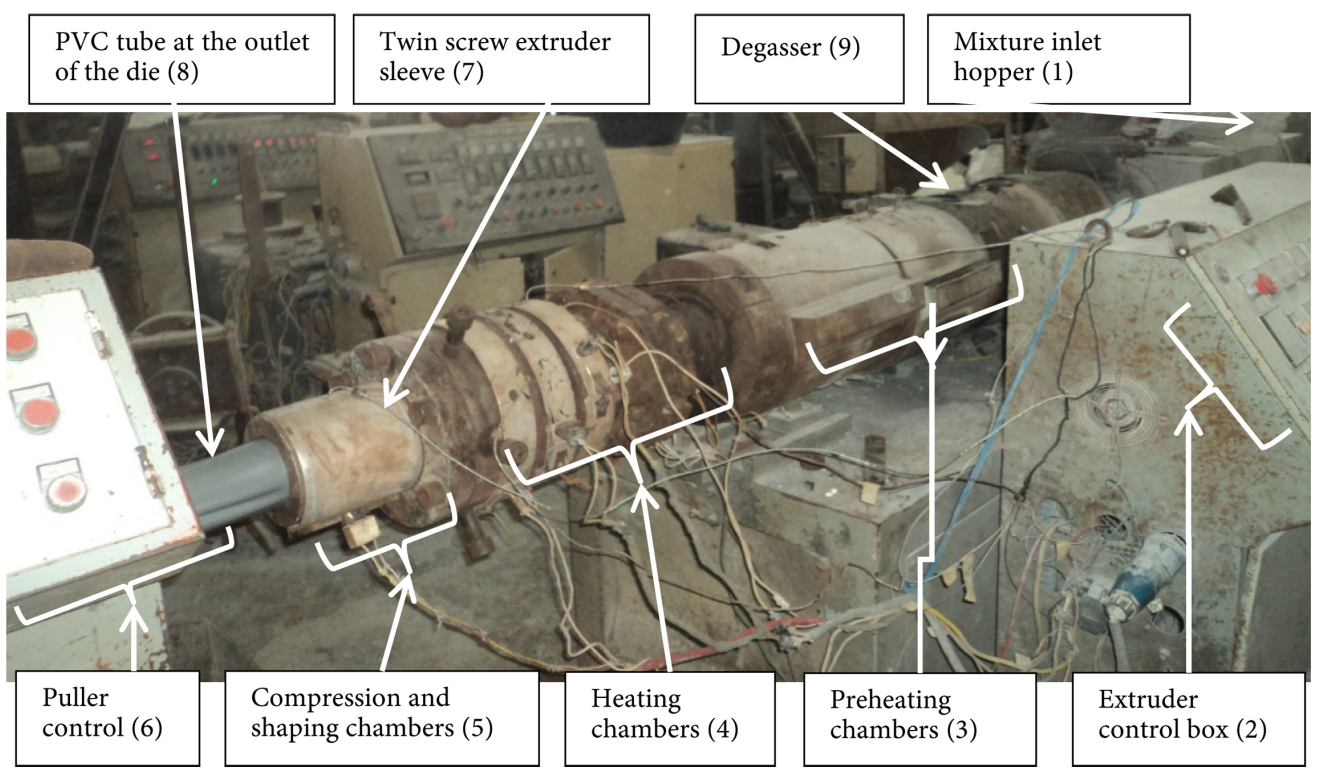

Figure 3. Extruder in the process of shaping the study materials. 
material. We present the important points of the continuous shaping of the extrusion, namely the hopper (1), which must be permanently full in order to limit the air intake (vacuum in the barrel), the deaerator (9) which ensures the humidity of the extrusion mixture, the sleeve (7) which ensures the continuous advance and the preparation of the shaping by passing through the preheating (3)-heating (4)-overheating and compression (5) of the mixture at the end of the sleeve, then finished by the pulling by passing through the calibrator and the cooler located in the control box (6). The sizing of the tubes at the end of the line stops the lengths of the tubes and sanctions the end of the production.

\subsection{Experimental Extrusion Methodology}

Table 3 below shows the steps we followed to achieve satisfaction with the extrusion of the tubes.

Table 3. Extrusion methodology.

\begin{tabular}{|c|c|c|}
\hline \multirow{8}{*}{$\begin{array}{l}\text { Preparation of } \\
\text { the extrusion }\end{array}$} & 1 & Install the $90 \mathrm{~mm}$ die and the $82 \mathrm{~mm}$ punch in the extruder barrel. \\
\hline & 2 & $\begin{array}{l}\text { Set the temperatures of the twin screw extruder in the order } 175^{\circ} \mathrm{C}, 175^{\circ} \mathrm{C}, 175^{\circ} \mathrm{C}, 185^{\circ} \mathrm{C}, 185^{\circ} \mathrm{C}, 185^{\circ} \mathrm{C} ; 190^{\circ} \mathrm{C} \text {, } \\
190^{\circ} \mathrm{C} \text {, representing respectively the temperatures of the preheating, degassing, heating, and shaping chambers of } \\
\text { the machine. }\end{array}$ \\
\hline & 3 & Turn on the electrical control box of the machine's heating system. \\
\hline & 4 & Allow to heat for the time necessary to allow the resin that could not be emptied to melt and free the screws. \\
\hline & 5 & Turn on the electric control box of the machine's screw system. \\
\hline & 6 & Let it run for the time necessary to completely release the screws from the sleeve. \\
\hline & 7 & Place the mixing powders in the order F0, F4.01, F12.54, F23.03, F32.01, F38.01, F51.02 near the extruder. \\
\hline & 8 & Make a vacuum pass (to make the sleeve completely empty and clean). \\
\hline \multirow{6}{*}{$\begin{array}{l}\text { Extrusion } \\
\text { itself } \\
(\text { step 1) }\end{array}$} & 1 & Load the F0 mixture and check the degassing (Pour the F0 mixture powder into the inlet hopper of the extruder. \\
\hline & 2 & Definitely adjust the sizer, the cooler. \\
\hline & 3 & Finally set the fencer. \\
\hline & 4 & Final adjustment of the chainsaw; \\
\hline & 5 & Let the extrusion of the F0 tubes follow its normal course. \\
\hline & 6 & $\begin{array}{l}\text { Make sure that the F0 mixture is completely finished in the hopper (Just a small amount of F0 powder is seen } \\
\text { before pouring the next mixture to avoid air ingress). }\end{array}$ \\
\hline \multirow{3}{*}{$\begin{array}{l}\text { Extrusion } \\
\text { itself } \\
\text { (step 2) }\end{array}$} & 1 & Load the mixture F4.01 and check the degassing as you go along. \\
\hline & 2 & Let the extrusion of the F4.01 tubes follow its normal course. \\
\hline & 3 & Ensure that the F4.01 mixture is completely finished in the hopper. \\
\hline \multirow{3}{*}{$\begin{array}{l}\text { Extrusion } \\
\text { itself } \\
\text { (step 3) }\end{array}$} & 1 & Load the mixture F12.54 and check the degassing as you go. \\
\hline & 2 & Let the extrusion of the F12.54 tubes follow its normal course. \\
\hline & 3 & Ensure that the F12.54 mixture is completely finished in the hopper. \\
\hline \multicolumn{3}{|c|}{ Proceed in the same way until the end of the extrusion (steps $4,5,6,7$ ) of formulations F23.03, F32.01, F38.01, F51.02 respectively. } \\
\hline \multicolumn{3}{|c|}{ Pass the tubes to quality control by the company's standards team. } \\
\hline \multicolumn{3}{|c|}{ Move on to packaging and storage. } \\
\hline \multicolumn{3}{|c|}{ Transport to the ENSP metallurgy laboratories (for analysis and characterization). } \\
\hline
\end{tabular}




\subsection{Conformity Test of the Elaborated Tubes}

\subsubsection{Physical Test}

Physical testing is done by observing the color of the tubes and the surface condition of the tubes.

\subsubsection{Test by Thermogravimetric and Differential Analysis}

The tube samples are cut from each formulation and powdered. The thermograms and the data of the TG and DSC recordings are obtained by the same principle as in the routine test of the mixtures and stripped accordingly.

\subsubsection{Test by FTIR Analysis}

The tube samples are cut from each formulation and powdered. The spectra and data of the TG and DSC recordings are obtained by the same principle as in the routine mixture test and analyzed accordingly.

\section{Results and Discussions}

\subsection{Formulation}

We calculated and prepared the powders for extrusion of unloaded PVC tubes called F0, PVC tubes loaded with $4.01 \%$ of palm kernel shell powder called F4.01; PVC tubes loaded with $12.54 \%$ of palm kernel shell powder called F12.54; PVC tubes loaded with $23.03 \%$ of the palm kernel shell powder called F23.03; PVC tubes loaded with $32.01 \%$ of the palm kernel shell powder called F32.01; PVC tubes loaded with $38.01 \%$ of the palm kernel shell powder called F38.01; PVC tubes loaded with 51.02\% of the palm kernel shell powder called F51.02.

\subsubsection{Dosage}

Table 4 gives the percentages of the ingredients in the formulation in percent (\%).

Table 4 shows that the formulation additives do not have a large percentage in a formulation. These low proportions are due to the fact that the raw PVC resin contains quantities of some of the processing additives during its refining.

Table 4. Percentage by weight of ingredients in the formulation.

\begin{tabular}{ccccccccc}
\hline & Resin & Stabilizer & Lubricant & Plasticizer & $\begin{array}{c}\text { Titanium } \\
\text { dioxide }\end{array}$ & Dye & $\begin{array}{c}\text { Hull } \\
\text { powder }\end{array}$ & units \\
\hline F0 & 96.96 & 2.82 & 1.63 & 1.34 & 0.22 & 0.04 & 0 & $\%$ \\
F4.01 & 89.22 & 3.48 & 1.74 & 1.28 & 0.23 & 0.04 & 4.01 & $\%$ \\
F12.54 & 81.17 & 3.17 & 1.7 & 1.16 & 0.23 & 0.03 & 12.54 & $\%$ \\
F23.03 & 71.31 & 2.78 & 1.6 & 1.02 & 0.22 & 0.03 & 23.03 & $\%$ \\
F32.01 & 62.51 & 2.75 & 1.59 & 0.89 & 0.22 & 0.03 & 32.01 & $\%$ \\
F38.01 & 56.23 & 2.93 & 1.69 & 0.81 & 0.23 & 0.02 & 38.01 & $\%$ \\
F51.02 & 43.38 & 2.64 & 1.52 & 0.63 & 0.2 & 0.02 & 51.02 & $\%$ \\
\hline
\end{tabular}


We have used all the ingredients of the formulation for obtaining the extruded PVC tubes by using calcium carbide $\left(\mathrm{CaCO}_{2}\right)$ of current consumption because we would like to use the powders of shells of palm kernel dura on an industrial scale. These values were used in the development of PVC/wood [5], PVC/corn powder [26], PVC/corn fiber [10]. We observe that the particularity of our formulation is that we use the cockle powder as the only load for the elaboration of the materials of our study which is a vegetable load. On the other hand, the works regularly met use the calcium carbide associated with the vegetable loads in the formulation of the elaboration of the materials of the study.

Table 5 represents the different masses of the formulations for the elaboration of unloaded PVC tubes and PVC tubes loaded with dura palm kernel shell powder at all the formulations obtained for the study.

We have chosen a fixed resin weight of $33.33 \mathrm{~kg}$ for all formulations, in order to limit the consumption of resin in the plant. This limitation of the total mass of the resin is due to the fact that we are in the experimental phase.

\subsubsection{Result of the Mixtures of the Ingredients of the Elaboration}

The mixed powders are packaged in plastic bags labeled according to the formulation, to maintain the mixing temperature before extrusion.

\subsubsection{Results of the Routine Test before Extrusion}

We present the results of thermograms of powders: palm kernel shells, raw PVC, 12.54\% loaded PVC (F12.54), 32.01\% loaded PVC (F32.01), 51.02\% loaded PVC (F51.02).

\subsubsection{Gravimetric and Differential Thermal Analysis Test}

We present the individual TG/DSC thermograms in Figure 4 with the aim of freeing up the understanding of the processes of the degradation evolution of both PVC and palm kernel shell powder and blends in order to ascertain on a case-by-case basis the condition of the palm kernel shell powder prior to shaping [15].

Table 5. Mass of the ingredients of the formulation.

\begin{tabular}{ccccccccc}
\hline & Resin & Stabilizer & Lubricant & Plasticizer & $\begin{array}{c}\text { Titanium } \\
\text { dioxide }\end{array}$ & Dye & $\begin{array}{c}\text { Hull } \\
\text { powder }\end{array}$ & units \\
\hline F0 & 33.33 & 1 & 0.58 & 0.48 & 0.08 & 0.01 & 0 & $\mathrm{Kg}$ \\
F4.01 & 33.33 & 1.3 & 0.65 & 0.48 & 0.09 & 0.01 & 1.5 & $\mathrm{Kg}$ \\
F12.54 & 33.33 & 1.3 & 0.7 & 0.48 & 0.09 & 0.01 & 5.15 & $\mathrm{Kg}$ \\
F23.03 & 33.33 & 1.3 & 0.75 & 0.48 & 0.1 & 0.01 & 10.77 & $\mathrm{Kg}$ \\
F32.01 & 33.33 & 1.47 & 0.85 & 0.48 & 0.12 & 0.01 & 17.07 & $\mathrm{Kg}$ \\
F38.01 & 33.33 & 1.73 & 1 & 0.48 & 0.13 & 0.01 & 22.5 & $\mathrm{Kg}$ \\
F51.02 & 33.33 & 2 & 1.15 & 0.48 & 0.15 & 0.01 & 38.67 & $\mathrm{Kg}$ \\
\hline
\end{tabular}




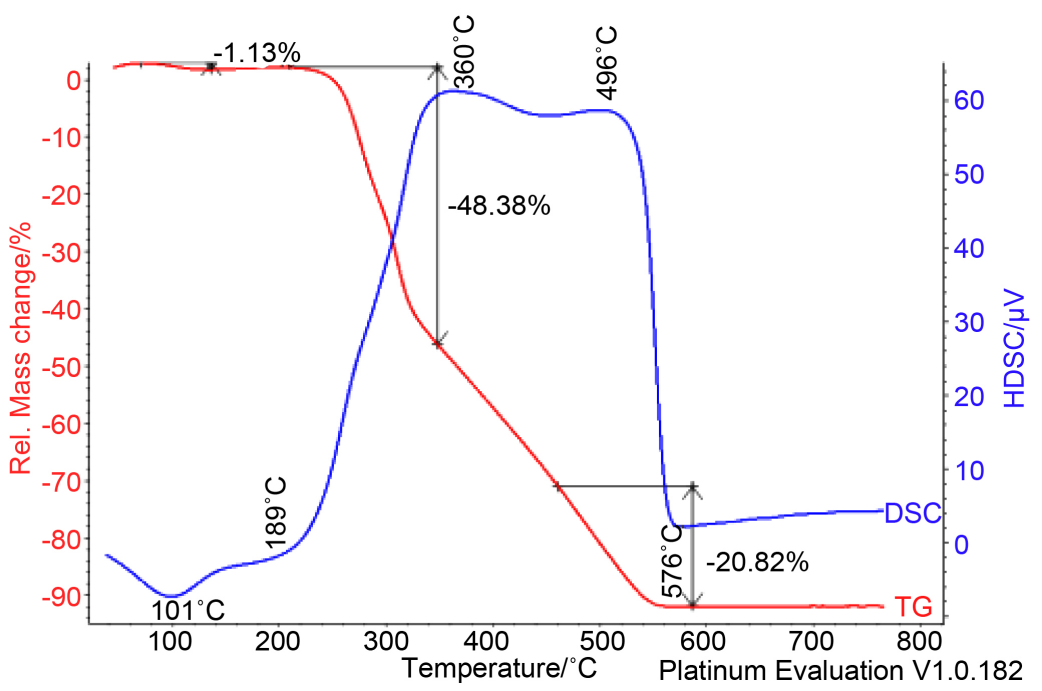

(a)

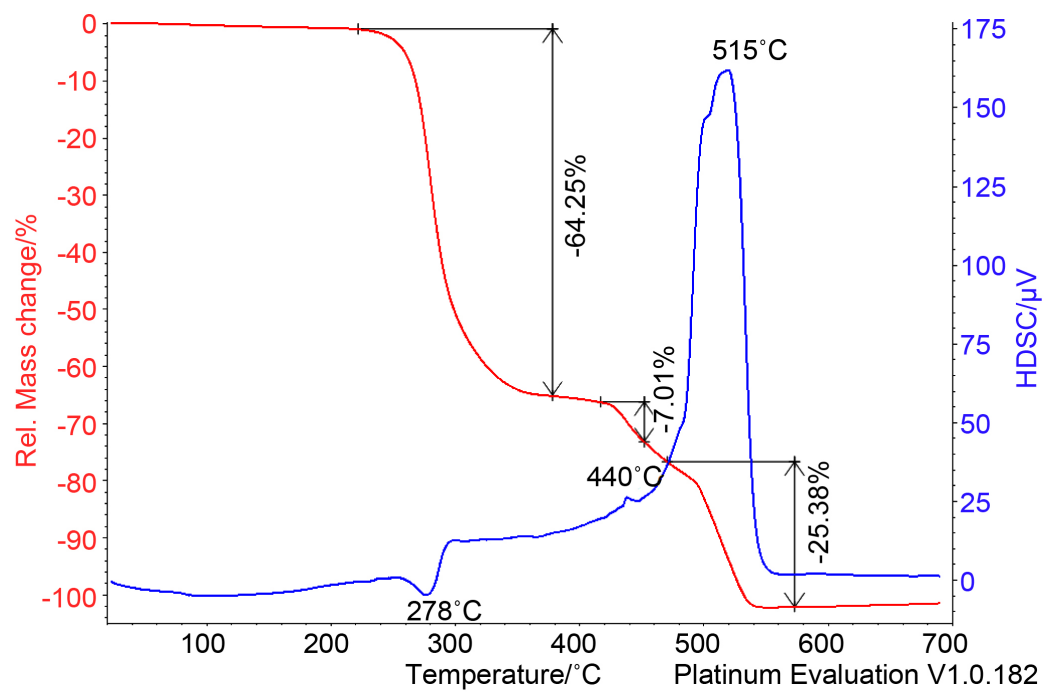

(b)

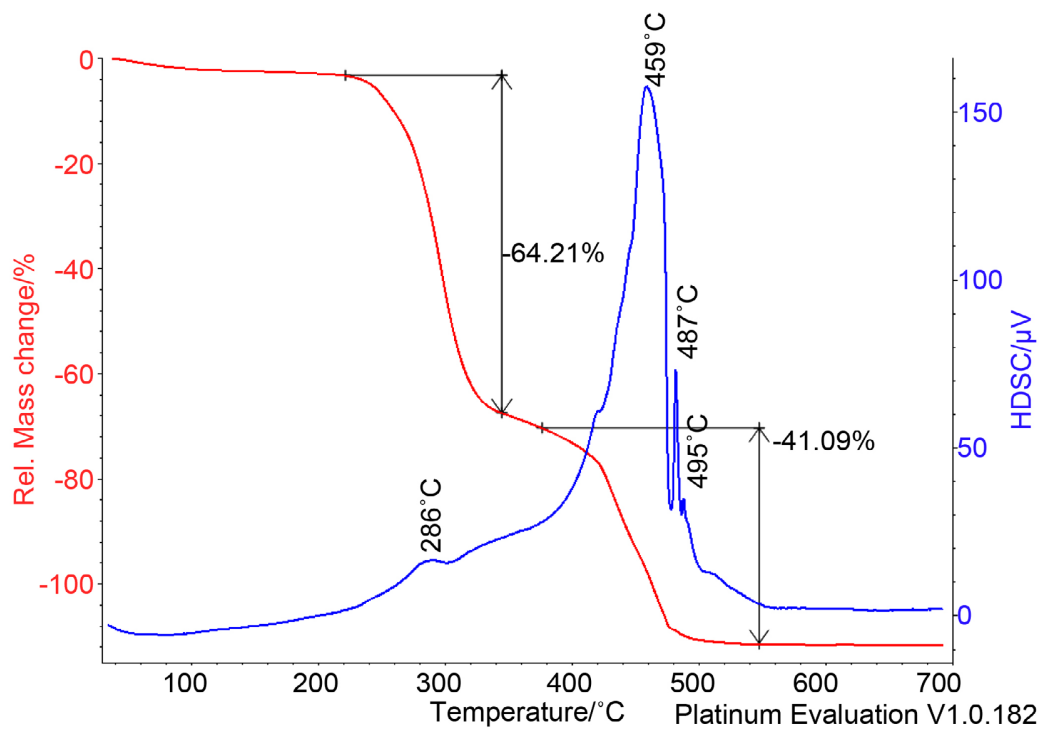

(c) 


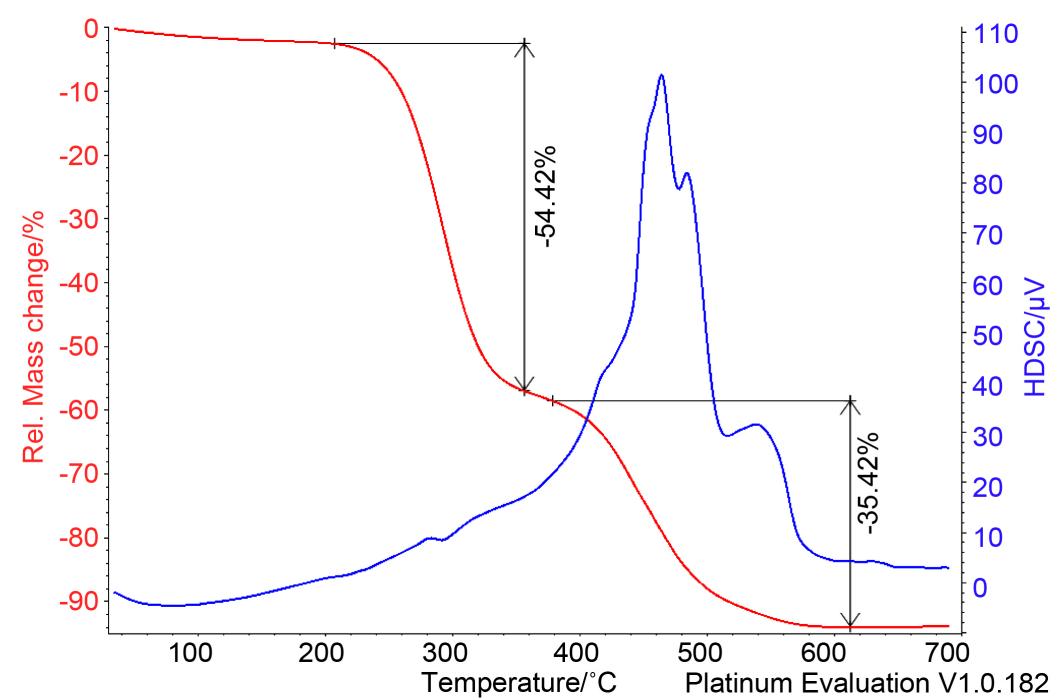

(d)

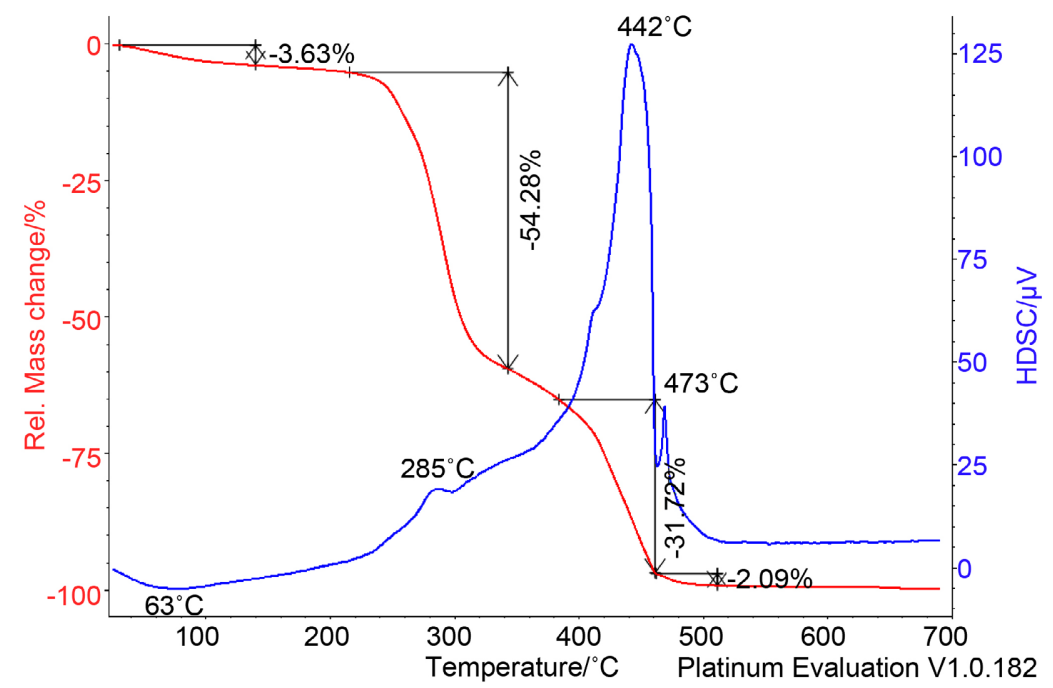

(e)

Figure 4. TG and DSC thermograms of the analyzed blend powders.

Figure 4 below shows the TG and DSC thermograms of: raw palm kernel shell powder Figure 4(a), raw PVC powder Figure 4(b), PVC (with additives) loaded respectively $12.54 \%$ Figure 4 (c), 32.01\% Figure 4(d) and 51.02\% Figure 4 (e) of palm kernel shell powder. The TG show for the PVC and loaded PVC blend powders, that there are 5 peaks of thermal degradation: dehydration, dehydrochlorination, condensation, fragmentation and ash with each time the mass losses. It can be seen that raw PVC has no free water but shell powder has free water [15].

Similarly, the hull powder shows 4 phases of degradation while the blend powders have 5 by observing the thermal degradation of the hull powder and that of the raw PVC and, comparing to different PVC blend powder with the hull powder, we find that the thermal degradation of the blends exactly matches both the raw PVC and the hull powder. 
The DSC shows endothermic peaks and the exothermic peaks characteristic of plastics (PVC) namely the glass transition, cold crystallization, melting, combustion and ash peaks [27]. The above results obtained show that hull powder is a good load for PVC extrusion.

\subsubsection{Fourier Transform Infrared Analysis Test of Blend Powders}

Similarly to thermal analysis, We present the individual FTIR spectra in Figure 5 with the aim of freeing up the understanding of the different probable groupings of both raw PVC and palm kernel shell powder and blends in order to ascertain case by case the chemical state of the tubes to be obtained prior to shaping [15]. Figure 5 shows the spectra of the following powders: raw palm kernel shell powder Figure 5(a), raw PVC powder Figure 5(b), PVC (with additives) loaded respectively $12.54 \%$ Figure $5(\mathrm{c})$ and $51.02 \%$ Figure $5(\mathrm{~d})$ of palm kernel shell powder.

Sat Nov 18 13:06:31 2017 (GMT+01:00)

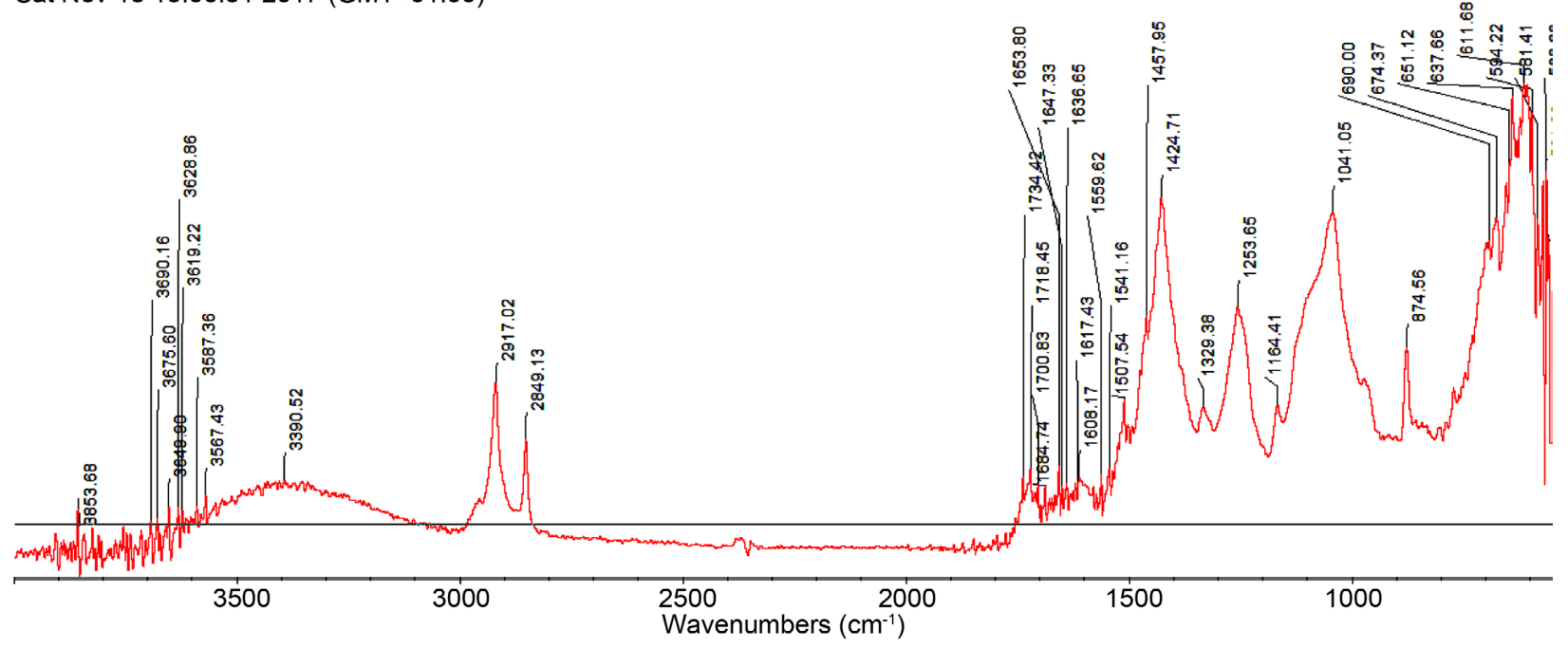

(a)

Sat Nov 18 12:55:50 2017 (GMT+01:00)

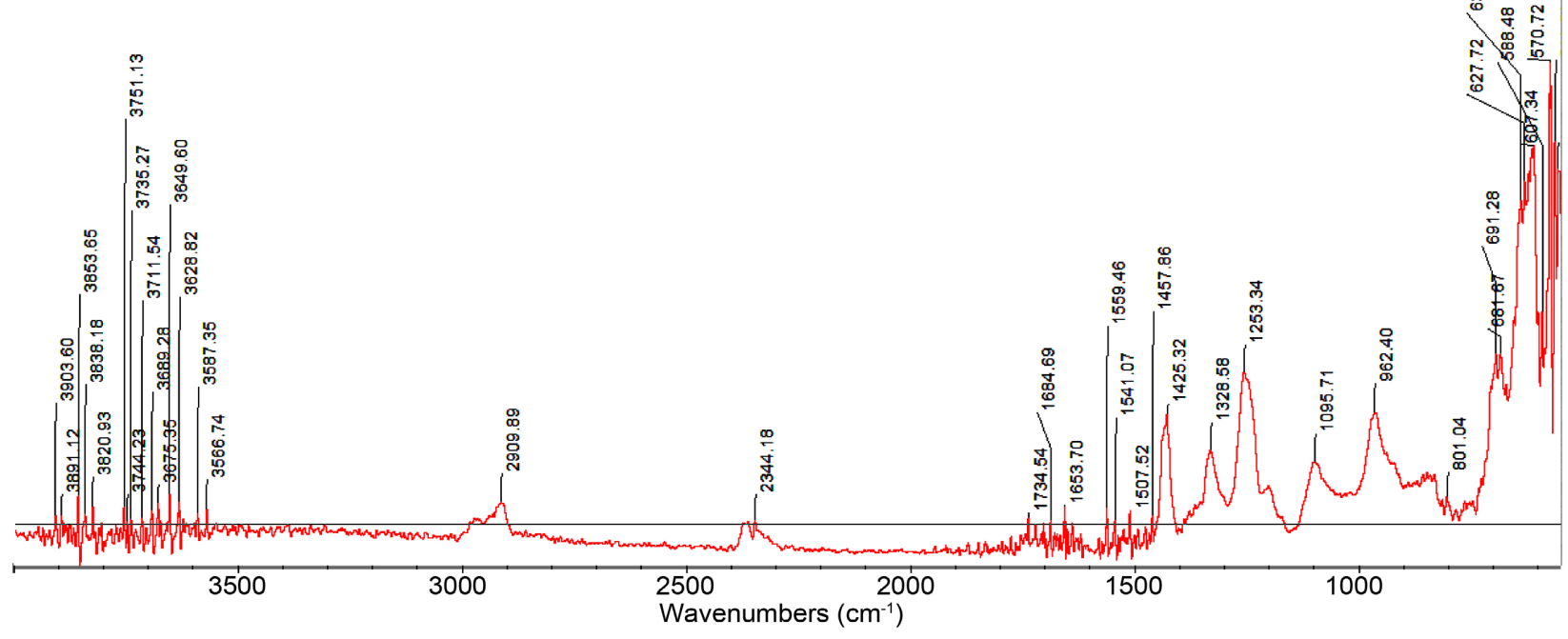

(b) 


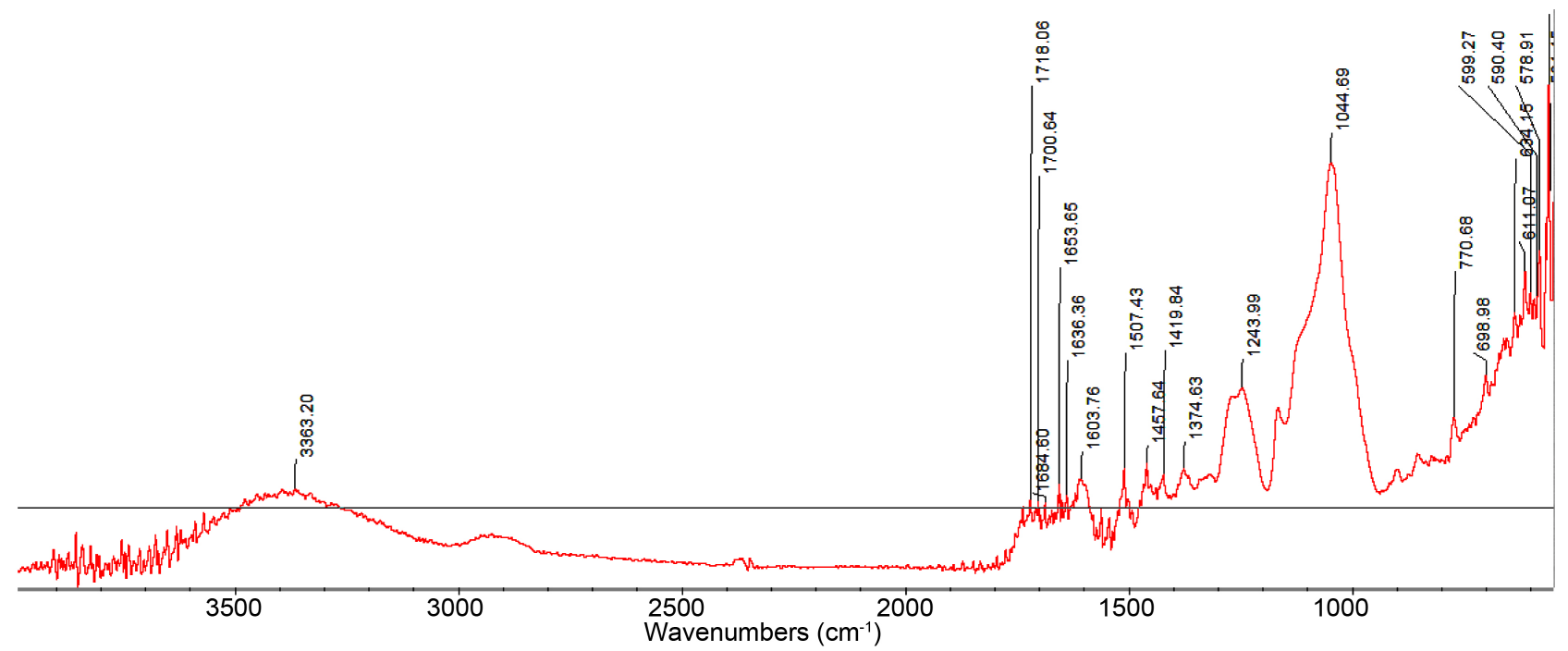

(c)

Sat Nov 18 12:48:17 2017 (GMT+01:00)

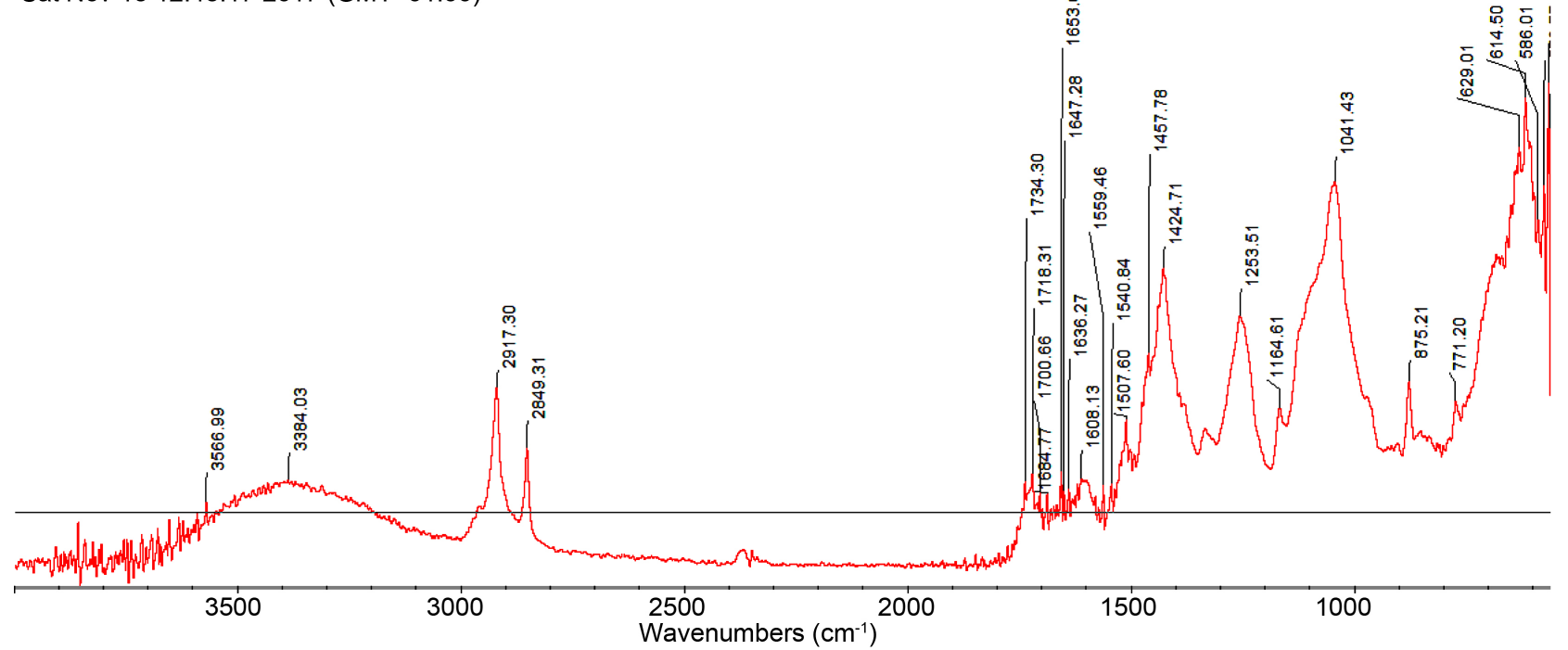

(d)

Figure 5. Fourier transform infrared spectra of the blend powders.

We obtain from Figure 5 that the prominent peaks of the mixtures at intensities in the vicinity of $3300 \mathrm{~cm}^{-1}$, can be attributed to $-\mathrm{O}-\mathrm{H}$ vibrations. The peaks of the mixtures in the vicinity of 2917 and $2849 \mathrm{~cm}^{-1}$, could be attributed to the -C-H grouping. The intensity peaks in the vicinity of $1424 \mathrm{~cm}^{-1}$ could be attributed to -C-H grouping or -C-H deformation.

The intensity peaks in the vicinity of $1424 \mathrm{~cm}^{-1}$ could be attributed to trans $-\mathrm{C}-\mathrm{H}$ in grouping mode or deformation mode. The intensity peaks near 1041 $\mathrm{cm}^{-1}$ could be attributed to -C-O groups. The intensity peaks in the vicinity of $874 \mathrm{~cm}^{-1}$ could be attributed to $-\mathrm{C}-\mathrm{Cl}$ groups. We note that at the intensity peaks in the vicinity of 3300 of $-\mathrm{O}-\mathrm{H}$, there is a creation of a new intermediate grouping between the PVC and the shell powder. This is due to the presence of cellulose in the shell powder which is absent in the PVC. The same observations are 
made in the vicinity of the peak at $1041 \mathrm{~cm}^{-1}$ where we observe a growth in the intensity of the PVC and a decrease in that of the shell powder. At the intensities in the vicinity of $2917,1424,1253$, a sharp decrease in intensity is observed in the different groups for the mixtures. These intensity variations show that the hull powder influences the PVC. These observations were obtained in his work on vegetable loads [5] [27] [28] [29].

\subsection{Discussion of the Routine Test}

We will say that the thermogravimetric and differential analyses showed the glass transition ( $\mathrm{Tg}$ ), cold crystallization (Tcf), melting (Tf), combustion (Tc) and ash (Tce) present in the blend powders at DSC and dehydration (Th and $\mathrm{Mh}$ ), dehydrochlorination ( $\mathrm{THCl}$ and $\mathrm{MHCl}$ ), condensation (Tco and $\mathrm{Mco}$ ), fragmentation (Tfr and Mfr), combustion (Tco and Mco) and ash (Tce and Mce) at TG. The raw PVC powder shows the same phases. There are changes in both the temperatures and masses of the mixtures during the degradation of PVC. These changes come from the presence of the hull powder contained in the mixture.

The Fourier Transform Infrared (FT-IR) results show a sharp decrease and a sharp increase in intensities in the different groupings for the blends. These increases and decreases in the intensities of the different groupings show that the hull powder will influence the PVCs and will help confirm the study material.

The DSC and TG show that the tubes we will obtain, will be a plastic material containing PVC and shell powder and that thermally, The additives will not influence the plastic material we will obtain. The same phenomenon occurs when we analyze the oven-transformed infrared spectra for all formulations.

The results obtained above show that the hull powder is a good load for PVC extrusion and that, whatever the percentage of palm kernel hull powder contained in the PVC, the extrusion will follow its course under good conditions.

\subsubsection{Extrusion Result}

Figure 6 shows the results of the extrusion of unloaded PVC tubes and PVC tubes loaded with palm kernel shell powder produced at the SOFAMAC factory.

We obtained tubes with an external diameter of $90 \mathrm{~mm}$ and an internal diameter of $82 \mathrm{~mm}$. These dimensions come from the die and the punch used in the extruder. Several works in the field of plastic extrusion use rectangular dies. These dies produce plate specimens, as in the case of work on the development of PVC/wood [5], the characterization of polypropylene and hemp fiber [7] [8] [10]. This is due to the shape of the specimens for the tests to be done in accordance with the standard.

We obtained tubes in the formulations F0 (Figure 6(a)), F4.01 (Figure 6(b)), F12.54 (Figure 6(c)), F23.03 (Figure 6(d)), F32.01 (Figure 6(e)), 38.01 (Figure 6(f)) then F51.02 (Figure 6(g)). The tubes were prepared under the same conditions. We only modified the additives, speeds, temperatures, distance between the die and the sizer, speed and distance of cooling of the extruder, compared to 


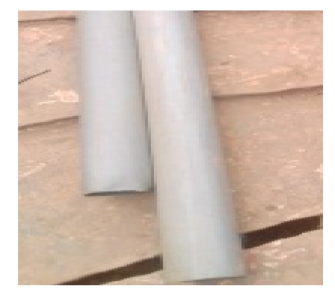

(a)

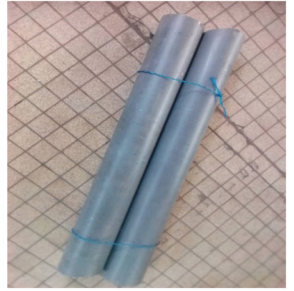

(d)

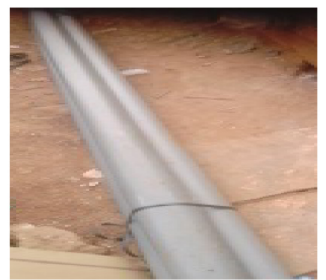

(b)

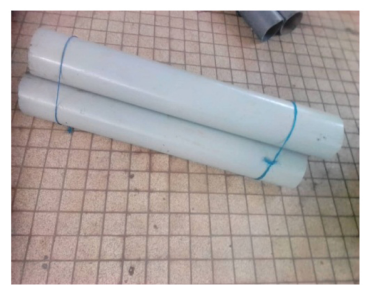

(c)

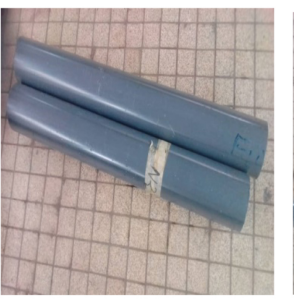

(e)

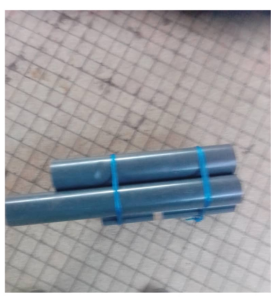

(f)

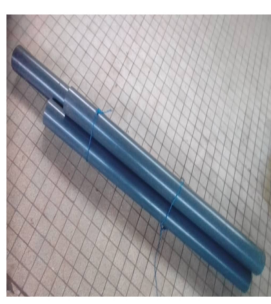

(g)

Figure 6. PVC tubes obtained.

the extrusion using calcium carbide as the usual load. These changes in parameters were reported in the literature [22].

The extrusion was done continuously. We cut the tubes in $2 \mathrm{~m}$ lengths. We obtained 6 pieces of tube of formulation F0; 10 pieces of tube of formulation F4.01, 10 pieces of tube of formulation F12.54, 8 pieces of tube of formulation F23.03, 6 pieces of tube of formulation F32.01, 4 pieces of tube of formulation F38.01 and 4 pieces of tube of formulation F51.02. We obtained a lesser quantity for the large loads (F32.01, F38.01, F51.02). This is due to the time taken to adjust the machine (change of temperatures, speed of the filler) which caused the presence of rejects at the level of the company's standards team.

\subsubsection{Results of the Conformity Tests of the Extrusion of the Elaborated PVC Tubes \\ 1) Results of the physical conformity tests}

We found that as the load increases, the tube becomes darker. This increase in coloring is due to the color and the dosage of the hull powder present in the mixture associated with the carbon black used as a colorant in the formulation. Table 6 below gives the results of the diameters, surface finishes, shapes and colours obtained and observed on the tubes of each formulation.

2) Results of the tests of conformity of the thermogravimetric and thermodifferential analyses

We interpret the thermograms obtained after the thermogravimetric and differential analyses of the elaborated tubes. We will insist especially on the different phase changes of the tubes for each formulation. We will present the DSC a part and Tg a part thermograms of the unloaded PVC tubes and the PVC tubes loaded with the hull powder, and then we give the results of their phase changes during degradation [24] [30].

\section{3) Results of thermo differential analysis}

Upon receipt of the TG/DSC thermograms and the data from the recordings 
Table 6. Color of extruded tubes by formulation.

\begin{tabular}{cccccccc}
\hline Formulations & F0 & F4.01 & F12.54 & F23.03 & F32.01 & F38.01 & F51.02 \\
\hline $\begin{array}{c}\text { External diameter } \\
\text { of the tubes }\end{array}$ & 90 & 90 & 90 & 90 & 90 & 90 & 90 \\
$\begin{array}{c}\text { Internal diameter } \\
\text { of the tubes }\end{array}$ & 82 & 82 & 82 & 82 & 82 & 82 & 82 \\
color & $\begin{array}{c}\text { White } \\
\text { grey }\end{array}$ & Light grey & grey & Dark grey & black & black & $\begin{array}{c}\text { Dark } \\
\text { black }\end{array}$ \\
Surface finish & $\begin{array}{c}\text { Very } \\
\text { smooth }\end{array}$ & $\begin{array}{c}\text { Very } \\
\text { smooth }\end{array}$ & smooth & smooth & $\begin{array}{c}\text { Medium } \\
\text { smooth }\end{array}$ & $\begin{array}{c}\text { Not } \\
\text { smooth }\end{array}$ & $\begin{array}{c}\text { Not } \\
\text { smooth }\end{array}$ \\
Form & Round & Round & Round & Round & Round & Round & Round \\
\hline
\end{tabular}

and, after careful study of the results of both the unloaded PVC tubes and the PVC tubes loaded with palm kernel shell powder at the above-mentioned formulations, we present separately the DSC thermograms in Figure 7 and the TG thermograms with the aim of freeing up the visibility of the contribution of the palm kernel shell powder in the phase changes of the processed PVC tubes.

4) DSC thermogram of PVC and PVC loaded with palm kernel shell powder

Figure 7 shows that all the tubes have the classical domains for a PVC loaded with plant fibers [29] [31] namely: the wet domain sanctioned by its moisture content $(\mathrm{Th})$, followed by the glassy domain at temperatures below the glass transition ( $\mathrm{Tg}$ ); the rubbery domain between $\mathrm{Tg}$ and cold crystallization (Tcf), the semi-crystalline domain between cold crystallization and melting (Tf); the molten liquid domain (Tlf) and finally the ash domain (Tce). We observe, confused with the glass transition, a fine endothermic peak reflecting a phenomenon called enthalpic relaxation [27] [32] [33]. The cold crystallization observed is a typical phenomenon of high molecular weight polymers such as PVC with vegetable loads which, when the molten polymer (liquid) is cooled, due to their high molar masses and the great length of their macromolecular chains, do not crystallize. The liquid polymer freezes in a disordered state which is the glassy state. Then when we heat this amorphous polymer, its chains begin to vibrate and eventually acquire enough energy to begin to move and eventually, after the passage of the glassy transition, to adopt positions favorable enough to crystallize before passing to the state of ash. This phenomenon has been demonstrated by several works [27] [30] [32] [33] [34].

DSC results of the extruded tubes.

From the thermograms of the differential thermal analyses in Figure 8, we obtained that:

The glass transition temperature $(\mathrm{Tg})$ of unfilled PVC tubes is $\mathrm{Tg}=108.78^{\circ} \mathrm{C}$, that of $12.54 \%$ filled PVC tubes is $\mathrm{Tg}=98.58^{\circ} \mathrm{C}$, that of $32.01 \%$ filled $\mathrm{PVC}$ tubes is $\mathrm{Tg}=96^{\circ} \mathrm{C}$ and that of $51.02 \%$ filled $\mathrm{PVC}$ tubes is $\mathrm{Tg}=76.56^{\circ} \mathrm{C}$.

The thermal combustion temperature $(\mathrm{Tc})$ of the unfilled PVC tubes is $\mathrm{Tc}=$ $494.71^{\circ} \mathrm{C}$, that of the $12.54 \%$ filled $\mathrm{PVC}$ tubes is $\mathrm{Tc}=485.58^{\circ} \mathrm{C}$, that of the 


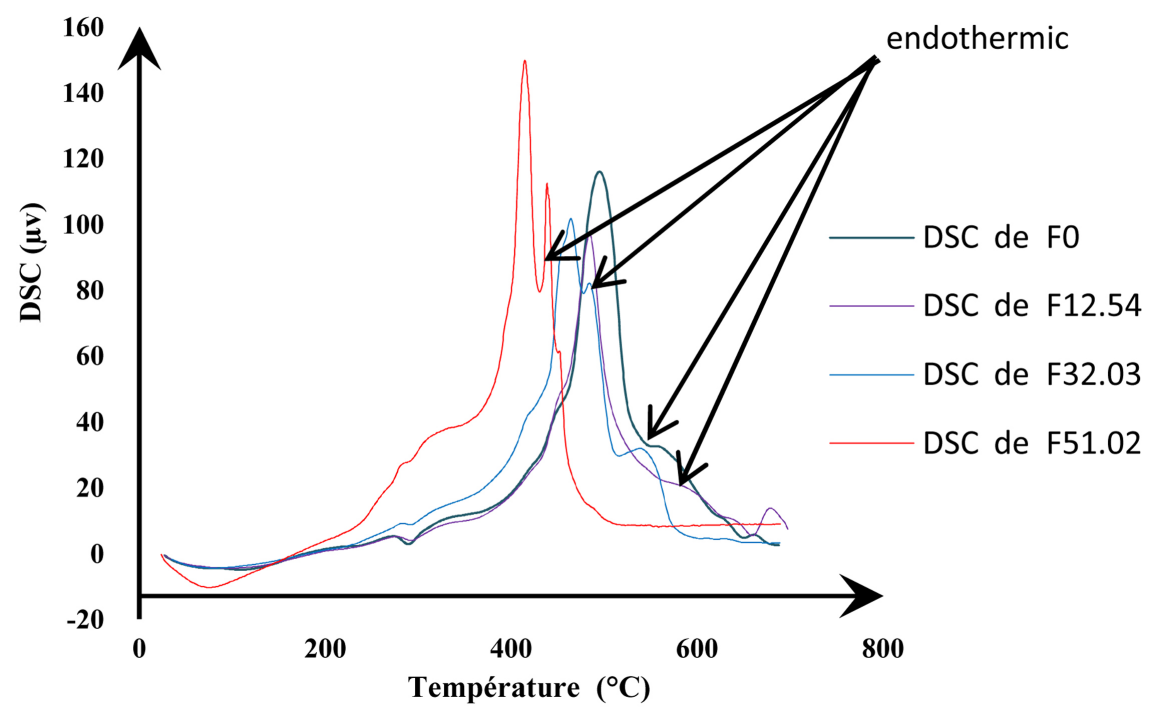

Figure 7. DSC thermograms of the elaborated tubes.

Phase change temperatures at the degradation of the elaborated tubes.

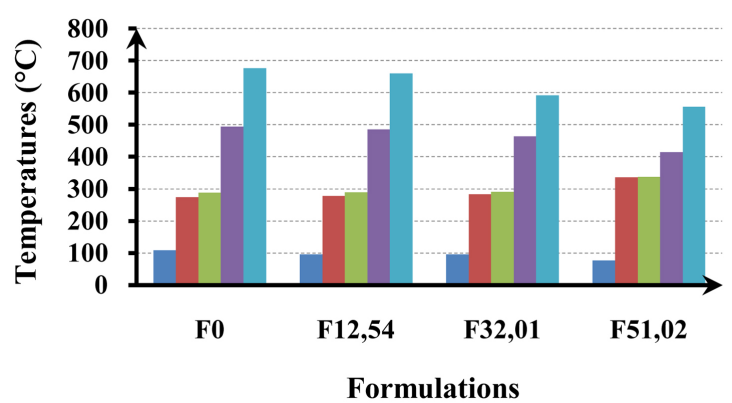

- Glass transition temperature, $\operatorname{Tg}\left({ }^{\circ} \mathrm{C}\right)$ - Crystallization temperature $\operatorname{Tcr}\left({ }^{\circ} \mathrm{C}\right)$. - Melting temperature $\mathrm{Tf},\left({ }^{\circ} \mathrm{C}\right)$. - Combustion temperature $\mathrm{Tc},\left({ }^{\circ} \mathrm{C}\right)$. - Ash temperature Tce, $\left({ }^{\circ} \mathrm{C}\right)$.

Figure 8. DSC thermogram results of the elaborated tubes.

32.01\% filled PVC tubes is $\mathrm{Tc}=464^{\circ} \mathrm{C}$, that of the $51.02 \%$ filled PVC tubes with palm kernel shell powder is $\mathrm{Tc}=414.56^{\circ} \mathrm{C}$.

The starting temperature of the ash (Tce) of the unfilled PVC is Tce = $475.71^{\circ} \mathrm{C}$, that of the PVC tubes filled with $12.54 \%$ is Tce $=659.58^{\circ} \mathrm{C}$, that of the PVC tubes filled with $32.01 \%$ is Tce $=591^{\circ} \mathrm{C}$, and that of the PVC tubes filled with $51.02 \%$ palm kernel shell powder is Tce $=555.56^{\circ} \mathrm{C}$.

The DSC results confirm the observations obtained in the literature [23] [35]. We obtained the glass transition of $\mathrm{Tv}=108.58^{\circ} \mathrm{C}$ at unloaded PVC while the literature gives $\mathrm{Tv}=98^{\circ} \mathrm{C}$ at unloaded PVC. This may be due to the percentage of plasticizer used. We observed that their plasticizer levels were higher than the ones we used. Also, the literature says that a high plasticizer content lowers the glass transition temperature of polymers but does not prevent the success of its shaping, which confirms the results of our work [23] [33].

\subsection{Results of Thermogravimetric Analysis}

\subsubsection{TG Thermogram of Unfilled and Filled PVC}

We received the thermograms and thermal analysis records from the laboratory. 
In Figure 9 below, we have shown the TG thermograms of all formulations in order to present the visual differences in phase changes to better appreciate the tubes produced and interpret them accordingly.

From Figure 9, we obtain for all the tubes that:

Dehydration begins around $30^{\circ} \mathrm{C}$ depending on the temperature at the beginning of the analyses and ends at the temperature Th. it produces a loss of mass Mh. it is the disappearance of free water $\left(\mathrm{H}_{2} \mathrm{O}\right)$ [36].

The dehydrochlorination begins around the temperature $\mathrm{THCl}$ by losing a mass $\mathrm{MHCl}$. This phase corresponds to the disappearance of $\mathrm{HCl}$ and polyene structures, as well as the possible formation of benzene, naphthalene and phenanthrene.

The condensation starts around the temperature TCO by losing a mass MCO. A significant amount of $\mathrm{HCl}$ is released, the polyene molecules rearrange and, through cyclization reactions, the cross-links form aromatic hydrocarbons and cullet.

The fragmentation starts around the temperature Tfr losing a mass Mfr. The $\mathrm{C}-\mathrm{C}$ bonds that formed the polymer chains and the hydrocarbons are broken. A large part of the material is pyrolyzed. Residual cullet remains at the temperature Tcar losing a residual mass Mcar.

\subsubsection{Results of the TG Thermograms of the Elaborated Tubes}

We obtain from Figure 10 and Figure 11 that:

The tubes of formulation F0: During the total dehydration of the unfilled PVC produced at $96.71^{\circ} \mathrm{C}$, we record that it loses $1.176 \%$ of its initial mass: this is the free water that evaporates. The further rise in temperature causes the dehydrochlorination of the PVC which begins at $244.71^{\circ} \mathrm{C}$ and ends at $335.71^{\circ} \mathrm{C}$ losing $60.41 \%$ of its initial mass before condensing. At the end of its condensation at $420.71^{\circ} \mathrm{C}$, it loses $6.05 \%$ of its initial mass then enters the fragmentation whose totality is reached towards $657.71^{\circ} \mathrm{C}$ leaving residual cullet of $3.76 \%$ of its initial mass: it is the ash.

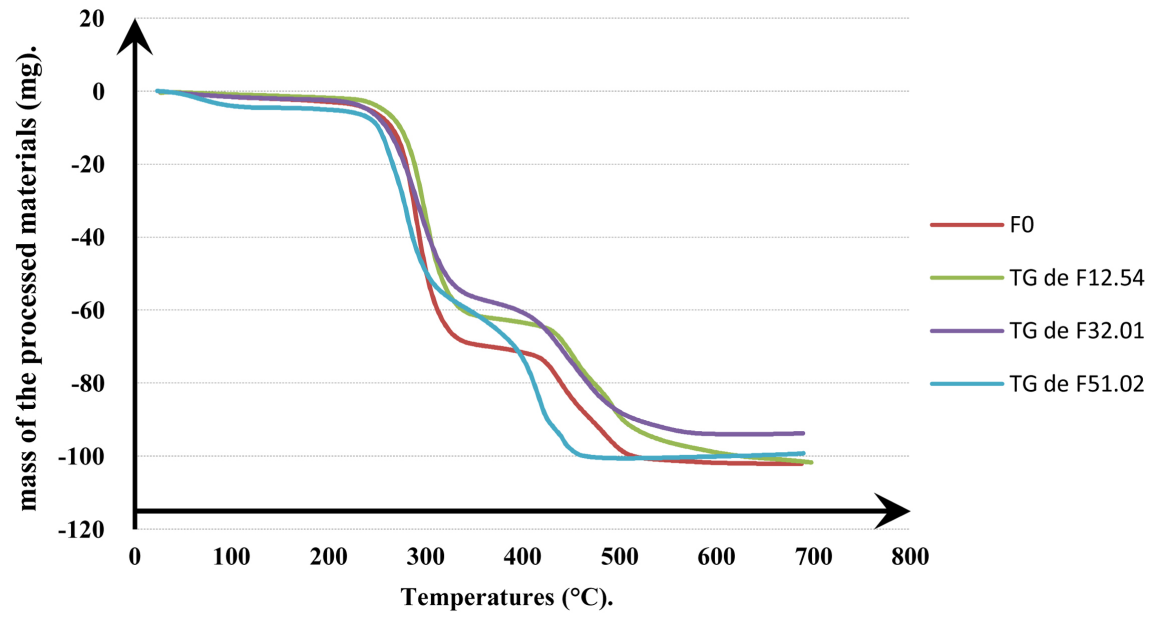

Figure 9. TG thermograms of the elaborated tubes. 
Temperatures at the phase changes of the elaborated PVC tubes

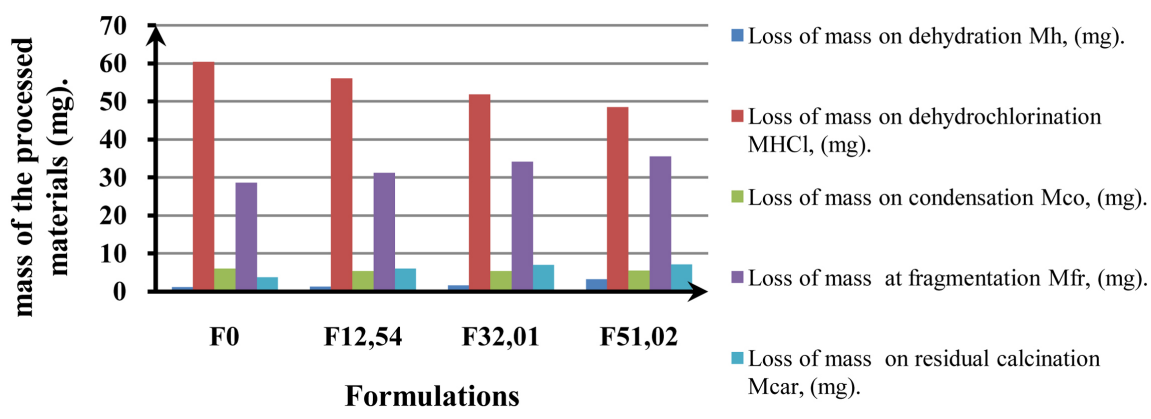

Figure 10. Result of the mass decrease at phase transitions of the elaborated tubes.

Temperatures at the decreases of mass of the elaborated tubes.

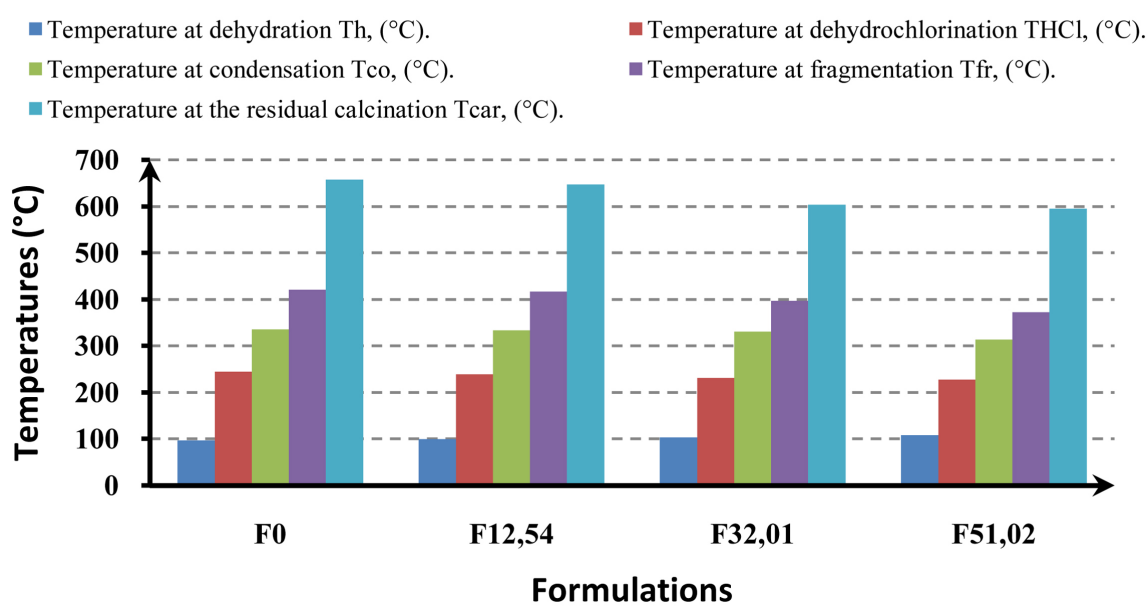

Figure 11. Results of the temperatures at the decreases of mass of the elaborated tubes.

The tubes of the formulation F12.54: during the dehydration of the PVC loaded with $12.54 \%$ of the powder of shells of palm kernel at the temperature of $99.58^{\circ} \mathrm{C}$, we obtain that it loses $1.315 \%$ of its initial mass: it is the disappearance of the free water. Then the rise in temperature creates the dehydrochlorination of PVC that begins at $238.58^{\circ} \mathrm{C}$ and ends at $333.58^{\circ} \mathrm{C}$ losing $56.032 \%$ of its initial mass before entering the condensation. Once condensation is complete at $420.71^{\circ} \mathrm{C}$, there is a reduction in mass equivalent to $6.05 \%$ of its initial mass and then fragmentation begins, which ends at $657.71^{\circ} \mathrm{C}$ leaving residual cullet of $6.053 \%$ in the crucible: this is the ash.

The tubes of the formulation F32.01: During the dehydration of the PVC loaded with $32.01 \%$ of the shell powder in the vicinity of $103^{\circ} \mathrm{C}$, the free water equivalent to $1.176 \%$ of its initial mass evaporates. The further rise in temperature causes the dehydrochlorination of the PVC which starts at $231^{\circ} \mathrm{C}$ and ends at $335^{\circ} \mathrm{C}$ losing $51.89 \%$ of its initial mass before condensing. At the end of condensation at $397^{\circ} \mathrm{C}$, it loses $6.979 \%$ of its initial mass and fragmentation begins and ends at $657.71^{\circ} \mathrm{C}$ leaving residual cullet of $6.979 \%$ of its initial mass: this is the ash that remains in the crucible.

The tubes of formulation F51.02 during the dehydration of the unfilled PVC 
elaborated at $107.56^{\circ} \mathrm{C}$, we record that it loses $3.278 \%$ of its initial mass: it is the free water which evaporates. The further rise in temperature causes the dehydrochlorination of the PVC which begins at $227.56^{\circ} \mathrm{C}$ and ends at $314.56^{\circ} \mathrm{C}$ losing $48.546 \%$ of its initial mass before condensing. At the end of the condensation towards $372.56^{\circ} \mathrm{C}$, it loses $5.517 \%$ of its initial mass then enters the fragmentation whose totality is reached towards $594.56^{\circ} \mathrm{C}$ leaving residual cullet of $73154 \%$ of its initial mass as ash in the crucible.

\subsection{Discussion}

The results of the DSC thermograms obtained are very similar to those obtained on the work done on PVC reinforced with vegetable fibers [5] [35]. The observations obtained on the samples with high load give the results of Tg to Tce reassuring the effectiveness of the temperature resistance of PVC/shell powder, then the presence of shell powder with high percentage of load presents a good degradation of the material at the end of life [26] [30] [37].

\subsubsection{Results of the Fourier Transform Infrared Analysis Tests}

We have performed the infrared analyses of all the elaborated tubes. We obtained the FTIR spectra with their recordings. The studies showed that the palm kernel shell powder influences considerably the chemical groups present in the unloaded PVC tubes. In order to release the visibility of the contribution of the palm kernel shell powder in the groups present in the PVC tubes loaded with palm kernel shell powder, we have presented in Figure 12 below the spectra obtained after the analysis of each tube of each formulation and for all the formulations of the study.

\subsubsection{Fourier Transform Infrared (FTIR) Spectra of the Developed Tubes}

Figure 12 shows the IR-TF spectra of the PVC and PVC tubes loaded with

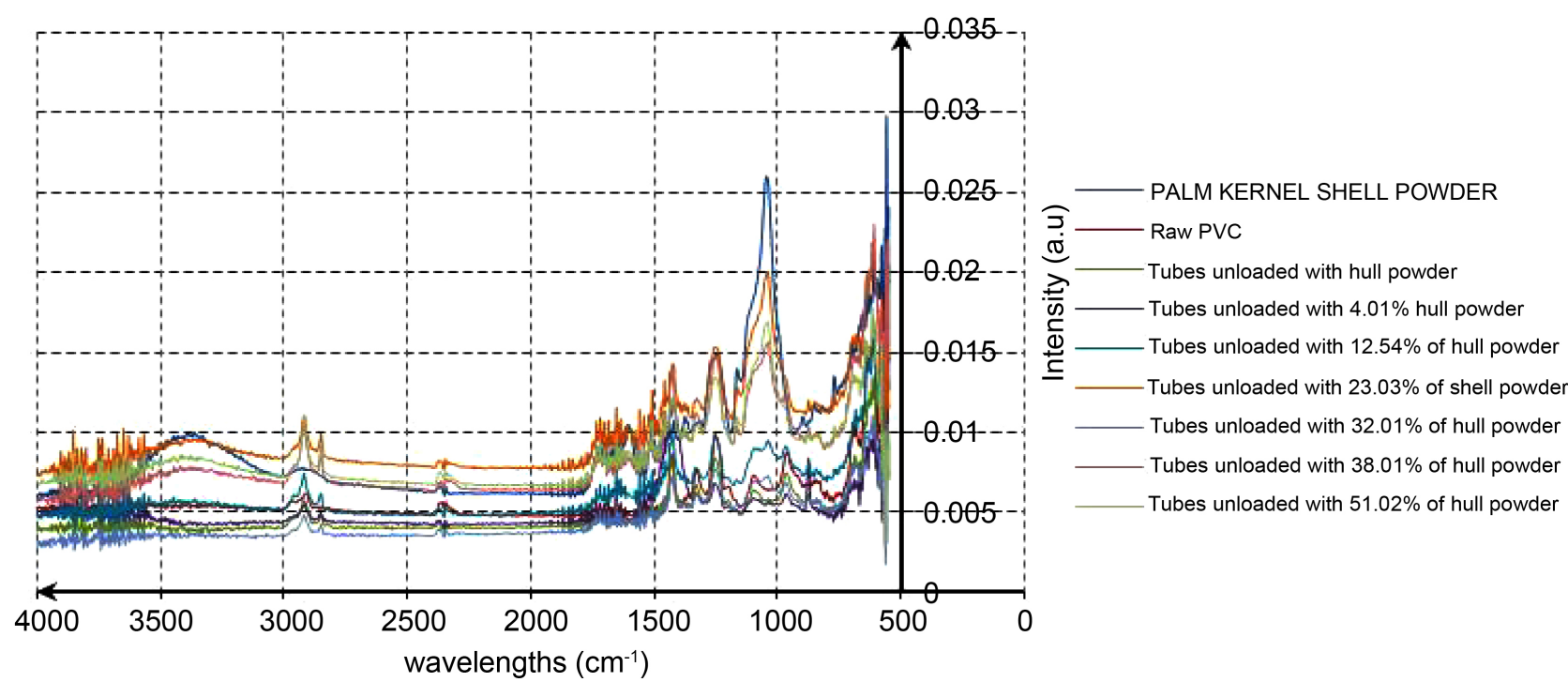

Figure 12. Fourier transform infrared spectra of the elaborated tubes. 
palm kernel shell powder from formulation F0 to formulation F51.02. We observe a series of background noises at wavelengths in the vicinity of $600 \mathrm{~cm}^{-1}$ and above $3500 \mathrm{~cm}^{-1}$. These noises come from the nature of the analysis and, when an element is far from the surface of the analysis, many electrons emitted will undergo inelastic shocks on their trajectories thus losing kinetic energy to come to constitute the background noise of the spectrum. These noises are present in all materials as well as raw PVC and palm kernel shell powder. These observations have been obtained in several works [38] [39] using spectroscopy for the evaluation of chemical parameters of materials.

We observe peaks characterizing the presence of PVC in the materials. These peaks are present at wavelengths around $800 \mathrm{~cm}^{-1}$ representing the $-\mathrm{C}-\mathrm{Cl}$ groups, then $1100 \mathrm{~cm}^{-1}$ representing the $-\mathrm{C}-\mathrm{O}$ groups present in the PVC.

The peaks characteristic of the presence of palm kernel shell powder are at wavelengths in the vicinity of $3300 \mathrm{~cm}^{-1}$ representing the $-\mathrm{O}-\mathrm{H}$ groups, showing the presence of cellulose in the shell powder, then in the vicinity of $2700 \mathrm{~cm}^{-1}$ representing the -C-H groups, showing the presence of lignin in the shell powder. Similar results have been obtained by several works [5] [15] [27] [32] [40] [41].

\subsubsection{Results of the Fourier Transform Infrared Analysis Test of the Elaborated Tubes}

We obtain from Figure 13 that, for:

The tubes of formulation $\mathrm{F} 0$, the $-\mathrm{O}-\mathrm{H}$ of alcohols vibrate at a wavelength equivalent to $3363.2 \mathrm{~cm}^{-1}$, the $-\mathrm{C}-\mathrm{H}$ of alkanes vibrate at $0 \mathrm{~cm}^{-1}$, the $\mathrm{C}=\mathrm{O}$ or the $\mathrm{C}-\mathrm{C}$ of aromatics at $1718.06 \mathrm{~cm}^{-1}$, the $\mathrm{C}-\mathrm{H}$ groups at $1374.64 \mathrm{~cm}^{-1}$, the $-\mathrm{C}-\mathrm{O}$ groups at $1044.64 \mathrm{~cm}^{-1}$, the $\mathrm{C}-\mathrm{Cl}$ groups at 770.68 and the $-\mathrm{CH}$ at $656.66 \mathrm{~cm}^{-1}$.

In the tubes of formulation $\mathrm{F} 4.01$, the $-\mathrm{O}-\mathrm{H}$ of alcohols vibrate at a wavelength equivalent to $3447.8 \mathrm{~cm}^{-1}$, the $-\mathrm{C}-\mathrm{H}$ of alkanes vibrate at $2918.33 \mathrm{~cm}^{-1}$, the $\mathrm{C}=\mathrm{O}$ or the $\mathrm{C}-\mathrm{C}$ of aromatics at $1762.75 \mathrm{~cm}^{-1}$, the $\mathrm{C}-\mathrm{H}$ groups at $1330.54 \mathrm{~cm}^{-1}$, the -C-O groups at $1100.53 \mathrm{~cm}^{-1}$, the $\mathrm{C}-\mathrm{Cl}$ groups at $874.6 \mathrm{~cm}^{-1}$ and the $-\mathrm{CH}$ at $663.13 \mathrm{~cm}^{-1}$.

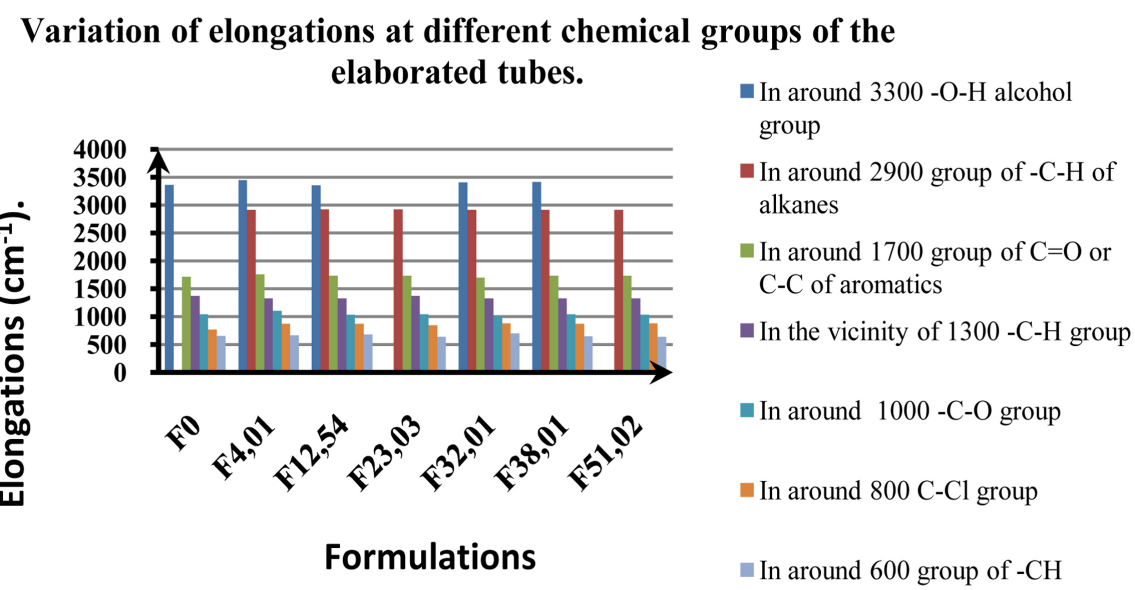

Figure 13. Fourier transform infrared analysis results of the developed tubes. 
The tubes of the formulation $\mathrm{F} 12.54$, the $-\mathrm{O}-\mathrm{H}$ of alcohols vibrate at a wavelength equivalent to $3351.03 \mathrm{~cm}^{-1}$, the $-\mathrm{C}-\mathrm{H}$ of alkanes vibrate at $0 \mathrm{~cm}^{-1}$, the $\mathrm{C}=\mathrm{O}$ or the $\mathrm{C}-\mathrm{C}$ of aromatics at $1731.37 \mathrm{~cm}^{-1}$, the $\mathrm{C}-\mathrm{H}$ groups at $1331.8 \mathrm{~cm}^{-1}$, the $-\mathrm{C}-\mathrm{O}$ groups at $1037.53 \mathrm{~cm}^{-1}$, the $\mathrm{C}-\mathrm{Cl}$ groups at $874.18 \mathrm{~cm}^{-1}$ and the $-\mathrm{CH}$ at $683.3 \mathrm{~cm}^{-1}$.

The tubes of formulation $\mathrm{F} 23.3$, the -O-H of alcohols vibrate at a wavelength equivalent to $0 \mathrm{~cm}^{-1}$, the $-\mathrm{C}-\mathrm{H}$ of alkanes vibrate at $2918.19 \mathrm{~cm}^{-1}$, the $\mathrm{C}=\mathrm{O}$ or the $\mathrm{C}-\mathrm{C}$ of aromatics at $1734.36 \mathrm{~cm}^{-1}$, the $\mathrm{C}-\mathrm{H}$ groups at $1374.91 \mathrm{~cm}^{-1}$, the $-\mathrm{C}-\mathrm{O}$ groups at $1041.13 \mathrm{~cm}^{-1}$, the $\mathrm{C}-\mathrm{Cl}$ groups at $847.43 \mathrm{~cm}^{-1}$ and the $-\mathrm{CH}$ at 638.44 $\mathrm{cm}^{-1}$.

The tubes of formulation F32.01, the -O- $\mathrm{H}$ of alcohols vibrate at a wavelength equivalent to $3405.98 \mathrm{~cm}^{-1}$, the $-\mathrm{C}-\mathrm{H}$ of alkanes vibrate at $2917.74 \mathrm{~cm}^{-1}$, the $\mathrm{C}=\mathrm{O}$ or the $\mathrm{C}-\mathrm{C}$ of aromatics at $1700.7 \mathrm{~cm}^{-1}$, the $\mathrm{C}-\mathrm{H}$ groups at $1329.37 \mathrm{~cm}^{-1}$, the -C-O groups at $1007.96 \mathrm{~cm}^{-1}$, the $\mathrm{C}-\mathrm{Cl}$ groups at $876.48 \mathrm{~cm}^{-1}$ and the $-\mathrm{CH}$ at $696.01 \mathrm{~cm}^{-1}$.

The tubes of the formulation F38.01, the $-\mathrm{O}-\mathrm{H}$ of alcohols vibrate at a wavelength equivalent to $3410.19 \mathrm{~cm}^{-1}$, the $-\mathrm{C}-\mathrm{H}$ of alkanes vibrate at $2918.06 \mathrm{~cm}^{-1}$, the $\mathrm{C}=\mathrm{O}$ or the $\mathrm{C}-\mathrm{C}$ of aromatics at $1734.36 \mathrm{~cm}^{-1}$, the $\mathrm{C}-\mathrm{H}$ groups at 1330.94 $\mathrm{cm}^{-1}$, the $-\mathrm{C}-\mathrm{O}$ groups at $1039.24 \mathrm{~cm}^{-1}$, the $\mathrm{C}-\mathrm{Cl}$ groups at $873.91 \mathrm{~cm}^{-1}$ and the $-\mathrm{CH}$ at $650.82 \mathrm{~cm}^{-1}$.

In the tubes of formulation F51.02, the - $\mathrm{O}-\mathrm{H}$ of alcohols vibrate at a wavelength equivalent to $0 \mathrm{~cm}^{-1}$, the $-\mathrm{C}-\mathrm{H}$ of alkanes vibrate at $2917.56 \mathrm{~cm}^{-1}$, the $\mathrm{C}=\mathrm{O}$ or the $\mathrm{C}-\mathrm{C}$ of aromatics at $1734.32 \mathrm{~cm}^{-1}$, the $\mathrm{C}-\mathrm{H}$ groups at $1329.67 \mathrm{~cm}^{-1}$, the $-\mathrm{C}-\mathrm{O}$ groups at $1038.72 \mathrm{~cm}^{-1}$, the $\mathrm{C}-\mathrm{Cl}$ groups at $875.01 \mathrm{~cm}^{-1}$ and the $-\mathrm{CH}$ at $638.09 \mathrm{~cm}^{-1}$.

\section{In Summary}

We have established a formulation sufficiently rigid to allow us to judge the powder of dura palm kernel shell micronized as a load for the production of the tubes of the study. We chose PVC for its ability to accept plant loads. We chose extrusion for its rigidity to accept the quality of the forming ingredients. The formulation of $0 \%$ palm kernel shells at $51 \%$ [34] reassures us that the shell powder does not limit the dosage. Finally, we have chosen to form the product in an industrial company and especially using a twin screw extruder [42]. All this is because we are working to enable economic operators to find investment areas in our results. In addition, the rigidity in the execution of this work has been because we have used the PVC whose success will allow researchers to extend without worries the work of dura palm kernel shells as a load on many other polymers (PE, PTFE, PP...) as is done with wood fiber [5], broom [10], hemp [7].

We have done routine tests to make the results scientific and serious. It is for this reason that the thermogravimetric and differential analysis and then Fourier transform infrared analysis showed perfect extrusion in each case of all the powders of mixture and that the materials that we will obtain are plastic mate- 
rials. Given that the resin of the work is PVC, these analyses have shown the presence of both PVC and palm kernel shell powder in the materials to be produced [5] [10] [15].

The extrusion is one of the techniques of the shaping of the plastic materials very hard so, this work mobilized all the team of competence of the company including the team of the standards. This is why we obtained, for the same initial mass of resin at the base of the shaping, not only insufficient quantities of tube for the characterization, but also the rigor in the execution of work. The shaping being continuous, the phase of the passage from a formulation to the following one caused losses because the visualization obliged us to reassure us that the transition is effectively passed particularly the rate of mixture obtained between the transitions between 2 formulations.

The tests of conformity allowed us to reassure that results were effective with the shaping, we obtained the obvious tests namely the touch then the visualization which allowed us to establish at the first approaches the effectiveness of the shaping. The satisfaction allows us to continue the work in the characterization and the various influences of the powder of shells of palm kernel dura on the behavior of PVC tubes extruded under various solicitations.

It is for this reason that we redid the analyses carried out on the routine tests namely the thermogravimetric and differential analyses and Fourier-transformed infrared analysis for the effectiveness of the shaping, namely,

- The difference between the transition temperatures of the mixture powder and the extruded tubes in the formulations carried out;

- The difference between the masses obtained in the phase transitions of the mixture powders and the extruded tubes in the different formulations;

- The difference between the different groupings both in the types of grouping and in the elongations for the blended powders and for the extruded tubes at the different formulations.

These results lead us to continue the work initially undertaken for some years on the shells of palm kernel dura [15], this part of the plant "the oil palm of the family ARECACEAE (palmae) of its scientific name Elaeisguinensis Jacq, referenced by comparison to the botanical collection of TAMAKI MARUHASHI of the National Herbarium of Cameroon" formerly considered as waste, in order to bring our contribution to the economic operators on the industrial valorization of the oil palm sector and especially our unwavering support on the promotion of the plastic recycling and biodegradable material for the fight against pollution [43] [44], problem worrying the researchers today in the world of the materials [45].

\section{Conclusion}

Industries use minerals as a load for the production of plastics. The disadvantage is that it does not degrade at the end of its life. Work has shown that vegetable loads improve this degradation. In this work, we use micronized palm kernel 
shell powders as the sole load for the production of PVC tubes with a company's industrial twin-screw extruder. We established the formulations from $0 \%$ to $51 \%$ load of the shell powder that we blended, used ATG/ATD and then FTIR to do routine testing of the blended powders, extruded all the formulations continuously and went on to compliance testing. The results for the formulations were: F0, F4.01, F12.54, F32.03, F32.01, F38.01, F51.02 where the numbers represent the load of the hull powder in the PVC. The mixing resulted in a perfectly homogeneous powder for each formulation. The routine test showed ATG/ATD and FTIR behaviour of the composite to be between the behaviour of PVC and the behaviour of palm kernel shell powder. Extrusion resulted in tubes with an outer diameter of $90 \mathrm{~mm}$ and an inner diameter of $82 \mathrm{~mm}$, perfectly round, ranging from smooth glossy to smooth rough, and with a colour range from grey-white to dark black. The DTA showed that the glass transition of the tubes decreases from $108.71^{\circ} \mathrm{C}$ to $76.56^{\circ} \mathrm{C}$, and the burning temperature from $494.71^{\circ} \mathrm{C}$ to $414.56^{\circ} \mathrm{C}$. TGA showed an increasing loss of mass on dehydration (from $1.17 \%$ to $3.27 \%$ ), fragmentation ( $28.60 \%$ to $35.50 \%$ ), residual cullet (3.76\% to $7.15 \%$ ); finally, IRFT showed for all tubes peaks characterizing the presence of PVC in the materials. These peaks are present at wavelengths in the vicinity of $800 \mathrm{~cm}^{-1}$ representing the $-\mathrm{C}-\mathrm{Cl}$ groups ranging from $770.68 \mathrm{~cm}^{-1}$ to 875.01 $\mathrm{cm}^{-1}$, at $1100 \mathrm{~cm}^{-1}$ representing the $-\mathrm{C}-\mathrm{O}$ groups ranging from $1044 \mathrm{~cm}^{-1}$ to $1038.74 \mathrm{~cm}^{-1}$. Then the peaks characteristic of the presence of palm kernel shell powder at wavelengths in the vicinity of $3300 \mathrm{~cm}^{-1}$ representing the $-\mathrm{O}-\mathrm{H}$ groups ranging from $3363.10 \mathrm{~cm}^{-1}$ to $3451.22 \mathrm{~cm}^{-1}$ showing the presence of cellulose in the shell powder, then in the vicinity of $2700 \mathrm{~cm}^{-1}$ representing $-\mathrm{C}-\mathrm{H}$ groups ranging from $2910.06 \mathrm{~cm}^{-1}$ to $2917.56 \mathrm{~cm}^{-1}$ showing the presence of lignin in the shell powder. The results obtained from the extrusion and compliance test show that PVC tubes loaded with hull powder are a new plastic material that deserves to be studied.

\section{Acknowledgements}

I would like to thank the General Manager of SOFAMAC in Yaoundé, SOA Cameroon.

\section{Conflicts of Interest}

The authors declare no conflicts of interest regarding the publication of this paper.

\section{References}

[1] Gasperi, J., Dris, R., Bonin, T., Rocher, V. and Tassin, B. (2014) Assessment of Floating Plastic Debris in Surface Water along the Seine River. Environmental Pollution, 195, 163-166. https://hal.archives-ouvertes.fr/hal-01067211 https://doi.org/10.1016/j.envpol.2014.09.001

[2] Bennani, A. (2006) Elaboration, comportement et durée de vie en fatigue du caoutchouc naturel renforcé de silice. Mécanique [physics.med-ph]. École Nationale 
Supérieure des Mines de Paris. NNT: 2006ENMP1403.

[3] Diemer, A. (2012) La technologie au cœur du développement durable: Mythe ou réalité? Innovations, 37, 73-94. https://doi.org/10.3917/inno.037.0073

[4] Shammya, A., et al. (2012) Physical, Optical and Thermal Properties of Graphite and Talc Filler Reinforced Polypropylene (PP) Composites. International Journal of Advanced Scientific and Technical Research, 5, 40-49.

[5] Augier, L. (2007) Etude de l'élaboration de matériaux composites PVC/bois à partir de déchets de menuiserie: Formulation, caractérisation, durabilité et recyclabilité. PhD, Institut National Polytechnique de Toulouse, Toulouse.

http://ethesis.inp-toulouse.fr/archive/00002291

[6] Elachaby, F. (2012) Mechanical and Thermal Properties of Polypropylene Reinforced with Alfa Fiber under Different Chemical Treatment. Materials and Design, 35, 318-322. https://doi.org/10.1016/j.matdes.2011.09.023

[7] Borchani, K. (2016) Développement d'un composite à base d'un polymère biodégradable et de fibres extraites de la plante d'Alfa. Polymères. Université de Lyon; École nationale d'ingénieurs de Sfax (Tunisie). Français.

[8] Bouhank, S. (2017) Elaboration de matériaux composites PVC/fibres de Genêt d'Espagne: Formulations et caractérisations. Thèse de doctorat.

[9] Sbiai, A. (2011) Matériaux composites a matrice époxyde chargée par des fibres de palmier dattier: Effet de l'oxydation au tempo sur les fibres. Thèse de doctorat, Institut National des Sciences Appliquées de Lyon, Lyon.

[10] Ilczyszyn, F. (2013) Caractérisation expérimentale et numérique du comportement mécanique des agro-composites renforcés par des fibres de chanvre. Matériaux et structures en mécanique [physics.class-ph]. Université de Technologie de Troyes, Troyes.

[11] Scida, D., Assarar, M., Ayad, R. and Poilâne, C. (2011) Effet de l'humidité sur le comportement mécanique des composites à fibres de lin. 17èmes Journées Nationales sur les Composites (JNC17), Poitiers, Jun 2011, 186.

[12] Zhou, N.T., Yao, L., Liang, Y.Z., Yu, B., Ye, M.Q., Shan, Z.D. and Qiu, Y.P. (2013) Improvement of Mechanical Properties of Ramie/Poly(Lactic Acid) (PLA) Laminated Composites Using a Cyclic Load Pre-Treatment Method. Industrial Crops and Products, 45, 94-99. https://doi.org/10.1016/j.indcrop.2012.12.014

[13] Chow, C., Xing, X. and Li, R. (2007) Moisture Absorption Studies of Sisal Fibre Reinforced Polypropylene Composites. Composites Science and Technology, 67, 306-319. https://doi.org/10.1016/j.compscitech.2006.08.005

[14] Lin, X., Tabil, L.G., Oguochan, I.N. and Panigrahi, S. (2008) Thermal Diffusivity, Thermal Conductivity, and Specific Heat of Flax Fiber-HDPE Biocomposites at Processing Temperatures. Composites Science and Technology, 68, 1753-1758. https://doi.org/10.1016/j.compscitech.2008.02.016

[15] Djomi, R., Meva'a, L., Nganhou, J., Mbobda, G., Njom, A., Bampel, Y. and Tchinda, J. (2018) Physicochemical and Thermal Characterization of Dura Palm Kernel Powder as a Load for Polymers: Case of Polyvinyl Chloride. Journal of Materials Science and Chemical Engineering, 6, 1-18. https://doi.org/10.4236/msce.2018.66001

[16] Kharrat, F., Khlif, M., Hilliou, L., Haboussi, M., Covas, J.A., Nouri, H. and Bradai, C. (2020) Minimally Processed Date Palm (Phoenix dactylifera L.) Leaves as Natural Fillers and Processing Aids in Poly(Lactic Acid) Composites Designed for the Extrusion Film Blowing of Thin Packages. Industrial Crops and Products, 154, Article ID: 112637. https://doi.org/10.1016/j.indcrop.2020.112637 
[17] Adesina, A.A., Nasser, M.N., Teixeira, P., Hilliou, L., Covas, J.A. and Hussein, I.A. (2015) Rheology of Organoclay Assisted Extrusion of HDPE Using Particle Image Velocimetry. Chemical Engineering Research and Design, 100, 113-125. https://doi.org/10.1016/j.cherd.2015.05.018

[18] Dansuk Industrial Ltd. Co. (2017-2018). Industrial Complex’ Head Office: 705.1DASHIHWA.

[19] Trotignon, J.P., Verdu, J., Dobracginsky, A. and Piperaud, M. (1996) Précis Matières Plastiques. AFNOR, Nathan.

[20] (2001) GÄCHTER/MÜLLER-Plastics Additives. 3rd Edition, Carl Hanser, Munich.

[21] Verdu, J. (1984) Vieillissement des plastiques. AFNOR Eyrolles.

[22] https://www.thermofisher.com/order/catalog/product/IQLAADGAAGFAHDMAZ $\underline{\mathrm{A}}$

[23] Trotignon, J.P., Verdu, J., Dobraczynski, A. and Piperaud, M. (2006) Précis des matières plastiques, Structures propriétés, mise en oeuvre, normalisation. Nathan 2 éd, $231 \mathrm{p}$.

[24] Hidayu, A.R., Mohamad, N.F., Matali, S. and Sharifah, A.S.A.K. (2013) Characterization of Activated Carbon Prepared from Oil Palm Empty Fruit Bunch Using BET and FT-IR Techniques. Procedia Engineering, 68, 379-384.

https://doi.org/10.1016/j.proeng.2013.12.195

[25] Rolet, A.P. and Bouaziz, R. (1972) Analyse thermique, tome 1: Changement de phase. Ed Gautiervillars.

[26] Jbilou, F., Galland, S., Ayadi, F., et al. (2011) Biodegradation of Corn Flour-Based Materials Assessed by Enzymatic, Aerobic, and Anaerobic Tests: Influence of Specific Surface Area. Polymer Testing, 30, 131-139. https://doi.org/10.1016/j.polymertesting.2010.11.007

[27] Ntenga, R., Mfoumou, E., Béakou, A., Tango, M., Kamga, J. and Ahmed, A. (2018) Insight on the Ultrastructure, Physicochemical, Thermal Characteristics and Applications of Palm Kernel Shells. Materials Sciences and Applications, 9, 790-811. https://doi.org/10.4236/msa.2018.910057

[28] Yang, H.P., Yan, R., Chen, H.P., Lee, D.H. and Zheng, C.G. (2007) Characteristics of Hemicellulose, Cellulose and Lignin Pyrolysis. Fuel, 86, 1781-1788. https://doi.org/10.1016/j.fuel.2006.12.013

[29] Dhakal, H.N., Arumugam, V., Aswinraj, A., Santulli, C., Zhang, Z.Y. and LopezArraiza, A. (2014) Influence of Temperature and Impact Velocity on the Impact Response of Jute/UP Composites. Polymer Testing, 35, 10-19. https://doi.org/10.1016/j.polymertesting.2014.02.002

[30] Zhang, J., Wang, Z., Du, M., Yao, X. and Hu, L. (2014) Physicochemical Properties of Camellia Nut Shell and Its Thermal Degradation Characteristics. Bioresources, 10, 647-659. https://doi.org/10.15376/biores.10.1.647-659

[31] Djidjelli, H., Kaci, M., Martinez-Vega, J.-J. and Benachour, D. (2004) Effects of Hydrothermal Ageing on the Thermal Behaviour of Poly(vinyl chloride) Filled with Wood Flour. Polymer International, 53, 1760-1765. https://doi.org/10.1002/pi.1572

[32] Augier, L., Sperone, G., Vaca-Garcia, C. and Borredon, M.-E. (2007) Influence of the Wood Fibre Filler on the Internal Recycling of Poly(vinyl chloride)-Based Composites. Polymer Degradation and Stability, 92, 1169-1176. https://doi.org/10.1016/j.polymdegradstab.2007.04.010

[33] Sombatsompop, N., Chaochanchaikul, K., Phromchirasuk, C. and Thongsang, S. (2003) Effect of Wood Sawdust Content on Rheological and Structural Changes, 
and Thermo-Mechanical Properties of PVC/Sawdust Composites. Polymer International, 52, 1847-1855. https://doi.org/10.1002/pi.1386

[34] Ulloa, C.A., Gordon, A.L. and García, X.A. (2009) Thermogravimetric Study of Interactions in the Pyrolysis of Blends of Coal with Radiata Pine Sawdust. Fuel Processing Technology, 90, 583-590. https://doi.org/10.1016/j.fuproc.2008.12.015

[35] Corbet, C. (1995) Mémotech—matières plastiques. Casteilla, Paris.

[36] Nekkaa, S., Guessoum, M., Grillet, A.C. and Haddaoui, N. (2012) Mechanical Properties of Biodegradable Composites Reinforced with Short Spartium junceum Fibers before and after Treatments. International Journal of Polymeric Materials and Polymeric Biomaterials, 61, 1021-1034. https://doi.org/10.1080/00914037.2011.617332

[37] Zhang, J., Ying, Y., Li, X. and Yao, X. (2018) FTIR and Thermogravimetric Analysis of Three Kinds of Nutshells. Natural Resources, 9, 313-325. https://doi.org/10.4236/nr.2018.98019

[38] Alghunaim, N.S. (2015) Spectroscopic Analysis of PMMA/PVC Blends Containing $\mathrm{CoCl}_{2}$. Results in Physics, 5, 331-336. https://doi.org/10.1016/j.rinp.2015.11.003

[39] Hidayu, A.R., Mohamad, N.F., Matali, S., et al. (2013) Characterization of Activated Carbon Prepared from Oil Palm Empty Fruit Bunch Using BET and FT-IR Techniques. Procedia Engineering, 68, 379-384.

https://doi.org/10.1016/j.proeng.2013.12.195

[40] Lydia, J., Alexander, J., Okon, E. and Aliyu, J. (2019) Statistical Analysis on Physico-Chemical Properties of Some Nigerian Clay Deposits. Journal of Materials Science and Chemical Engineering, 7, 52-63. https://doi.org/10.4236/msce.2019.78007

[41] Krimm, S., Liang, C.Y. and Sutherland, G.B.B.M. (1956) Infrared Spectra of High Polymers. II. Polyethylene. The Journal of Chemical Physics, 25, 549. https://doi.org/10.1063/1.1742963

[42] Nagaki, W., Doki, N., Yokota, M., Yamashita, K., Kojima, T. and Tanaka, T. (2021) Control of Crystal Size and Morphology of Calcium Carbonate Crystal Polymorphism. Journal of Materials Science and Chemical Engineering, 9, 38-45. https://doi.org/10.4236/msce.2021.94005

[43] Liu, C. (2012) Discussion of New Padding Method in DES Encryption. Journal of Software Engineering and Applications, 5, 20-22.

https://doi.org/10.4236/jsea.2012.512B004

[44] El-Zaher, N., Melegy, M. and Guirguis, O. (2014) Thermal and Structural Analyses of PMMA/TiO ${ }_{2}$ Nanoparticles Composites. Natural Science, 6, 859-870. https://doi.org/10.4236/ns.2014.611083

[45] Lee, J., Shim, M. and Kim, S. (2001) Thermal Degradation of Epoxy/Natural Zeolite Composites. Journal of Materials Science, 6, 4405-4409.

https://doi.org/10.1023/A:1017918400130 